\title{
Antitumor Phenylpropanoids Found in Essential Oils
}

\author{
Adriana Andrade Carvalho, ${ }^{1}$ Luciana Nalone Andrade, ${ }^{2}$ \\ Élida Batista Vieira de Sousa, ${ }^{3}$ and Damião Pergentino de Sousa ${ }^{2,3}$ \\ ${ }^{1}$ Núcleo de Farmácia, Universidade Federal de Sergipe, 58051-970 Lagarto, SE, Brazil \\ ${ }^{2}$ Departamento de Farmácia, Universidade Federal de Sergipe, 49100-000 São Cristóvão, SE, Brazil \\ ${ }^{3}$ Departamento de Ciências Farmacêuticas, Universidade Federal da Paraíba, CP 5009, 58051-970 João Pessoa, PB, Brazil
}

Correspondence should be addressed to Damião Pergentino de Sousa; damiao_desousa@yahoo.com.br

Received 5 July 2014; Accepted 12 October 2014

Academic Editor: Gagan Deep

Copyright (C) 2015 Adriana Andrade Carvalho et al. This is an open access article distributed under the Creative Commons Attribution License, which permits unrestricted use, distribution, and reproduction in any medium, provided the original work is properly cited.

\begin{abstract}
The search for new bioactive substances with anticancer activity and the understanding of their mechanisms of action are highpriorities in the research effort toward more effective treatments for cancer. The phenylpropanoids are natural products found in many aromatic and medicinal plants, food, and essential oils. They exhibit various pharmacological activities and have applications in the pharmaceutical industry. In this review, the anticancer potential of 17 phenylpropanoids and derivatives from essential oils is discussed. Chemical structures, experimental report, and mechanisms of action of bioactive substances are presented.
\end{abstract}

\section{Introduction}

Cancer is a global health concern that causes mortality in both children and adults. More than 100 distinct types and subtypes of cancer can be found within specific organs [1]. Despite the success of several cancer therapies, an ideal anticancer drug has not been discovered, and numerous side effects limit treatment. However, research into new drugs has revealed a variety of new chemical structures and potent biological activities that are of interest in the context of cancer treatment.

Essential oils are natural products that are a mixture of volatile lipophilic substances. The chemical composition of essential oils includes monoterpenes, sesquiterpenes, and phenylpropanoids, which are usually oxidized in an aliphatic chain or aromatic ring. Several studies have shown that this chemical class has several biological activities, including analgesic, anticonvulsant, and anti-inflammatory effects [24]. Antitumor activity has been reported for essential oils against several tumor cell lines [5-7], and these oils contain a high percentage of phenylpropanoids, which are believed to contribute to their pharmacological activity $[8,9]$.

This paper presents a literature review of phenylpropanoids from essential oils with respect to antitumor activity, with chemical structures and names of bioactive compounds provided. The phenylpropanoids presented in this review were selected on the basis of effects shown in specific experimental models for evaluation of antitumor activity and/or by complementary studies aimed at elucidating mechanisms of action (Table 1). The selection of essential oil constituents in the database was related to various terms, including essential oils and phenylpropanoids, as well as names of representative compounds of chemical groups, and refined with respect to antitumor activity, cytotoxic activity, and cytotoxicity. The search was performed using scientific literature databases and Chemical Abstracts Service (CAS) in November 2013.

\section{Phenylpropanoids}

2.1. Eugenol. Eugenol is the active component of essential oil isolated from clove (Syzygium aromaticum) and has antimutagenic, antigenotoxic, and anti-inflammatory properties [10]. Eugenol also has cytotoxic activity. This drugs can induce cell death in several tumor and cell types: mast cells [11-13], breast adenocarcinoma [13], melanoma cells [14-16], leukemia [14, 17], colon carcinoma [18], cervical carcinoma 
[19-23], prostate cancer [24], submandibular gland adenocarcinoma [25], human dental pulp [26], murine peritoneal macrophages [27], androgen-insensitive prostate cancer, oral squamous carcinoma $[17,28]$, human submandibular gland carcinoma $[29,30]$, salivary gland [30], gingival fibroblasts [31-33], hepatoma [34], human dental pulp cells [35], human gingival fibroblasts, and epidermoid carcinoma cells derived from human submandibular gland [36, 37]. Furthermore, eugenol is neither carcinogenic nor mutagenic and is not cytotoxic in lymphocytes [14]. Isoeugenol was found to be more toxic than eugenol when the cytotoxicity of isoeugenol, bis-eugenol, and eugenol was tested in HSG (human submandibular gland adenocarcinoma) cell lines [25]. In this way, Atsumi and collaborators [37] compared the cytotoxicity of dehydrodiisoeugenol, alpha-di-isoeugenol, isoeugenol, eugenol, and bis-eugenol in a gland tumor cell line (HSG) and normal human gingival fibroblasts (HGF). Both the cytotoxic activity and the DNA synthesis inhibitory activity of these compounds against the salivary gland tumor cell line (HSG) and normal human gingival fibroblasts (HGF) were greatest in dehydrodiisoeugenol and alpha-di-isoeugenol, followed by isoeugenol, which showed greater activity than eugenol [37].

Synergistic effects have been demonstrated for eugenol with gemcitabine and fluorouracil, which potentiated its cytotoxic effect on HeLa cells (human cervical carcinoma) $[19,20,38]$. Eugenol also significantly decreased expression of Bcl-2, COX2, and IL-1b in the HeLa cell line [20]. Atsumi and collaborators [39] demonstrated that the effects of eugenol on ROS production were biphasic, with production enhanced at lower eugenol concentrations $(5-10 \mu \mathrm{M})$ and inhibited at higher concentrations $(500 \mu \mathrm{M})$. Suzuki and collaborators [40] demonstrated that eugenol stimulated production of superoxide $\left(\mathrm{O}_{2}{ }^{-}\right)$free radicals in guinea pig neutrophils without lag time.

Eugenol halts cells in the replication phase, suggesting that cells stop to repair DNA damage and either reenter the cell cycle or, in cases of massive DNA damage, activate apoptosis. Melanoma cells treated with eugenol remain in the $\mathrm{S}$ phase and undergo apoptosis, and eugenol treatment upregulates numerous enzymes involved in the base excision repair pathway, including E2F family members [15].

In another study, eugenol at higher doses induced chromosomal aberrations, with significant increases (3.5\%) in aberrant cells at a concentration of $2500 \mu \mathrm{M}$ in V79 cells (Chinese hamster lung fibroblast). Eugenol was also assayed for genotoxic activity via inhibition of topoisomerase II and showed dose-dependent inhibition [41].

The chemopreventive potential of eugenol was also studied [10]. Using in vivo methods, Pal and collaborators [10] showed that eugenol inhibits skin carcinogenesis induced by dimethylbenz[a]anthracene (DMBA) croton oil in mice, probably due to inhibition of proliferation-associated genes (c-Myc and $\mathrm{H}$-ras) and antiapoptotic gene $\mathrm{Bcl} 2$, along with upregulation of proapoptotic genes Bax, p53, and active caspase-3 [10]. Kaur and collaborators [42] studied the chemopreventive effect of eugenol in DMBA/TPA-induced carcinogenesis in murine skin. They showed that topical application of eugenol resulted in a marked decline in hyperplasia, epidermal ODC activity, protein expression of iNOS and COX-2, and secretion of proinflammatory cytokines, all of which are classical markers of inflammation and tumor promotion [42]. In addition, eugenol has been shown to produce antioxidant effects via free radical scavenging activity and reduction of ROS [22, 36, 43]. Atsumi and collaborators [36] showed that visible-light irradiation and elevation of the $\mathrm{pH}$ of the eugenol-containing medium resulted in significantly lower cell survival in HSG cultures in comparison with eugenol alone.

In vivo murine assays have also demonstrated the antitumor potential of eugenol. Treatment of female B6D2F1 mice bearing B16 melanoma allografts with $125 \mathrm{mg} / \mathrm{kg}$ of eugenol resulted in a small, but highly significant $(P=0.0057)$, 2.4day tumor growth delay. Furthermore, the treated animals had no fatalities that were attributed to metastasis or tumor invasion, which is indicative of the ability of eugenol to suppress melanoma metastasis [15]. Jaganathan and collaborators [44] also demonstrated the antitumor potential of eugenol using an in vivo assay, in which a dose of $100 \mathrm{mg} / \mathrm{kg}$ caused $24.35 \%$ tumor growth inhibition and inhibited the growth of Ehrlich ascites by $28.88 \%$. In contrast, Tangke Arung and collaborators [45] showed that $100 \mu \mathrm{g} / \mathrm{mL}$ eugenol inhibited melanin formation by more than $42 \%$ in the B16 melanoma cell line in vitro, with cytotoxicity in $5 \%$ of cells. At a higher concentration of $200 \mu \mathrm{g} / \mathrm{mL} 23 \%$ cytotoxicity was observed, which demonstrated that eugenol could be useful as a skinwhitening agent for the treatment of hyperpigmentation [45].

Furthermore, it has been demonstrated that eugenol, when mixed with zinc oxide, has a restorative effect on dental erosion and demineralization [46]. Using human dental pulp cells (D824) it was observed that eugenol had a cytotoxic effect, with reduction of cell growth and inhibition of colonyforming cell [35]. D824 cells have the potential for metabolic activation, because they are a mixed-cell population composed of many types of cells, and thus the cytotoxic activity of eugenol could be attributable to eugenol metabolites. However, Marya and collaborators [46] showed a hemolytic effect of eugenol, which could be a possible side effect of this drug. In addition, Anpo and collaborators [35] showed that eugenol reduced growth and survival of human dental pulp cells, as well as collagen synthesis and bone sialoprotein (BSP) expression, which play a critical role in physiological and reparative dentinogenesis. Eugenol is a phenylpropanoid with promising antitumor drug profile. Further studies to elucidate the mechanisms that mediate the adverse effects of eugenol are necessary.

2.2. Methyleugenol, Isoeugenol, Methylisoeugenol, and $1^{\prime}-H y d-$ roxymethyleugenol. Methyleugenol is a substituted alkenylbenzene found in a variety of foods and essential oils. It is structurally similar to eugenol and found in many plant species [47]. Methyleugenol produced cytotoxic effects in rat and mouse hepatocytes [47, 48] and leukemia [48]. Methyleugenol also produced genotoxicity in mice [47] and in cultured cells [49] and caused neoplastic lesions in the livers of Fischer 344 rats and B6C3F1 mice [47].

Isoeugenol is a phenylpropanoid produced by plants. As a flavoring agent, isoeugenol is added to nonalcoholic drinks, baked foods, and chewing gums. In male F344/N rats, 

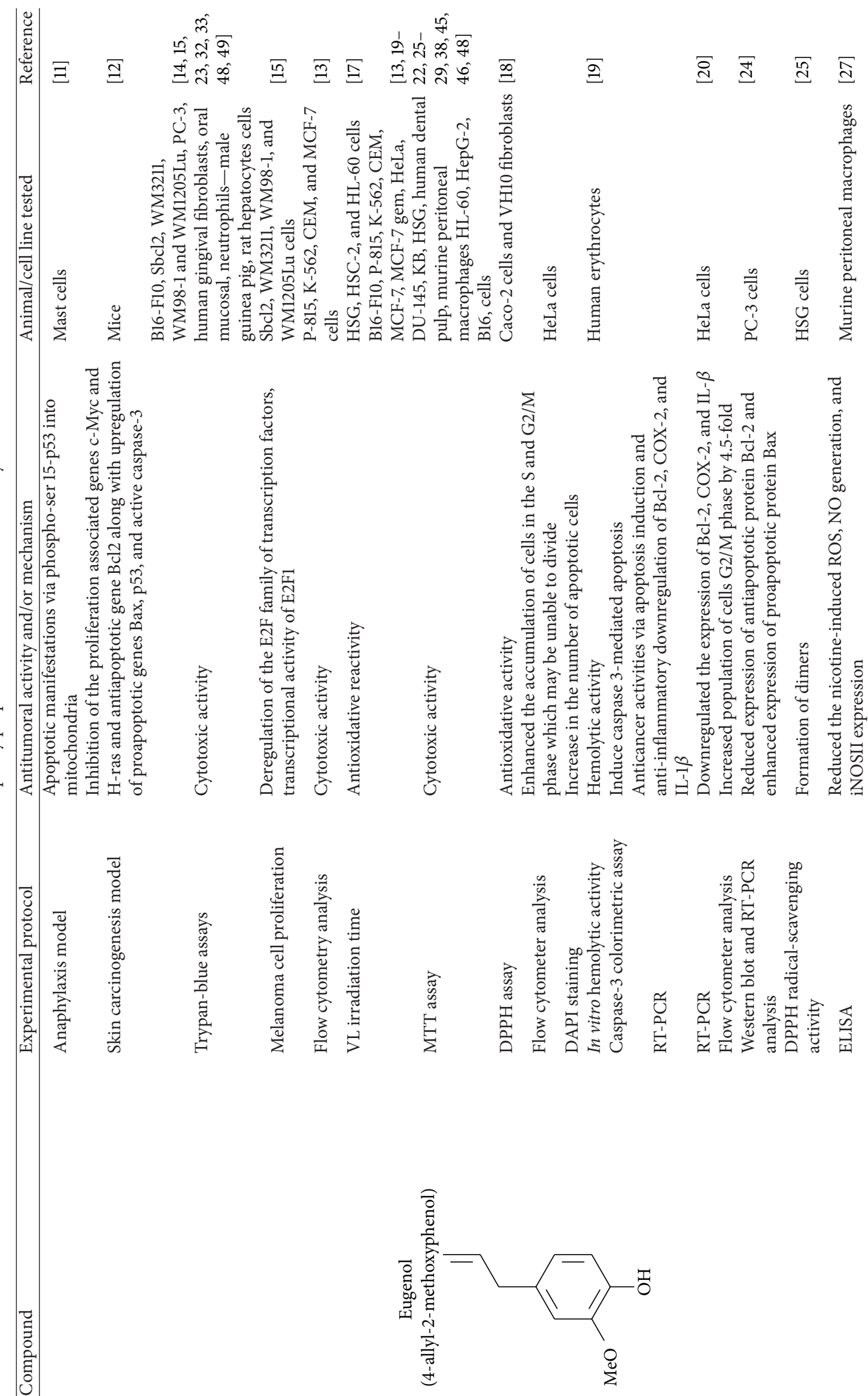


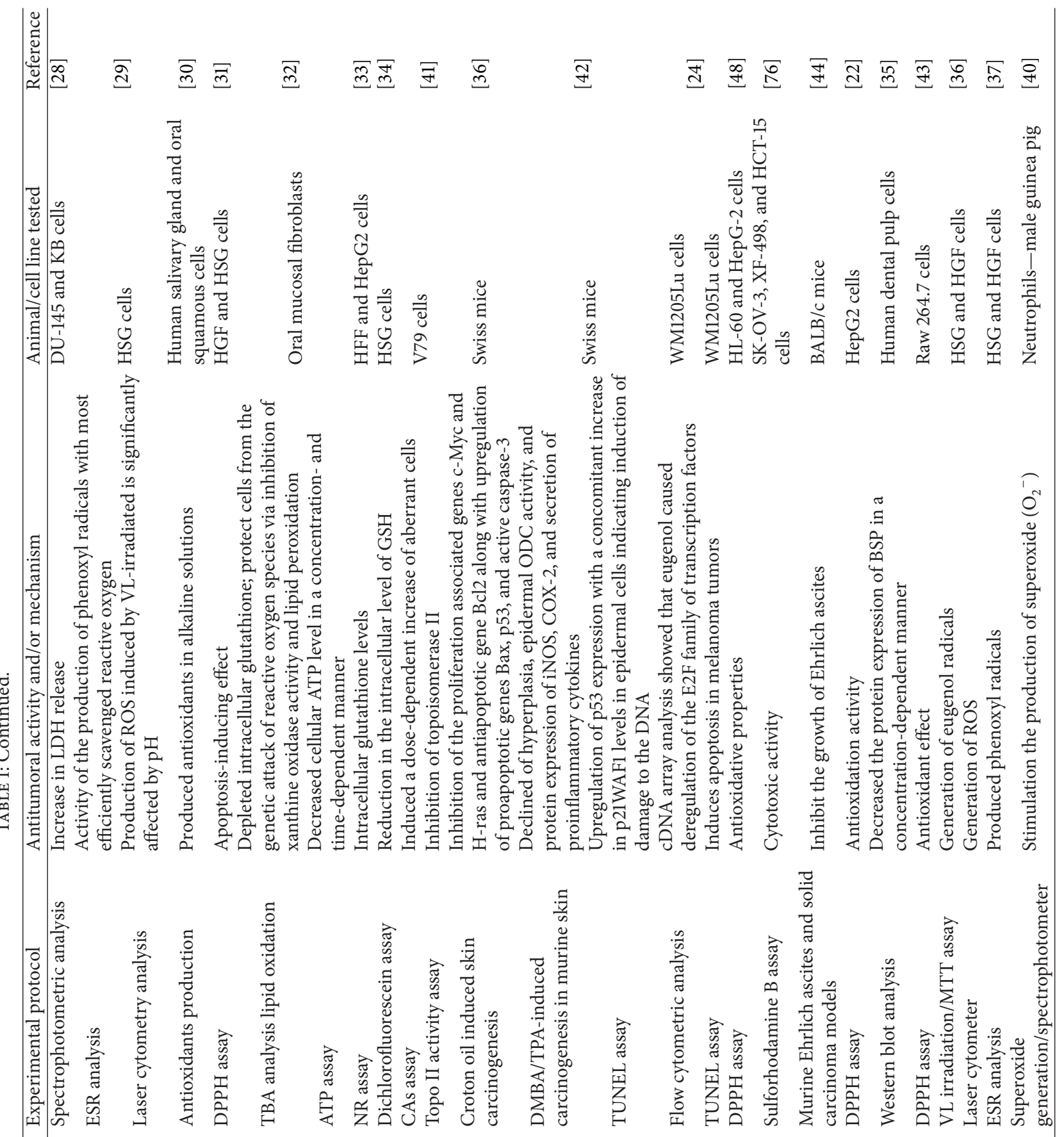




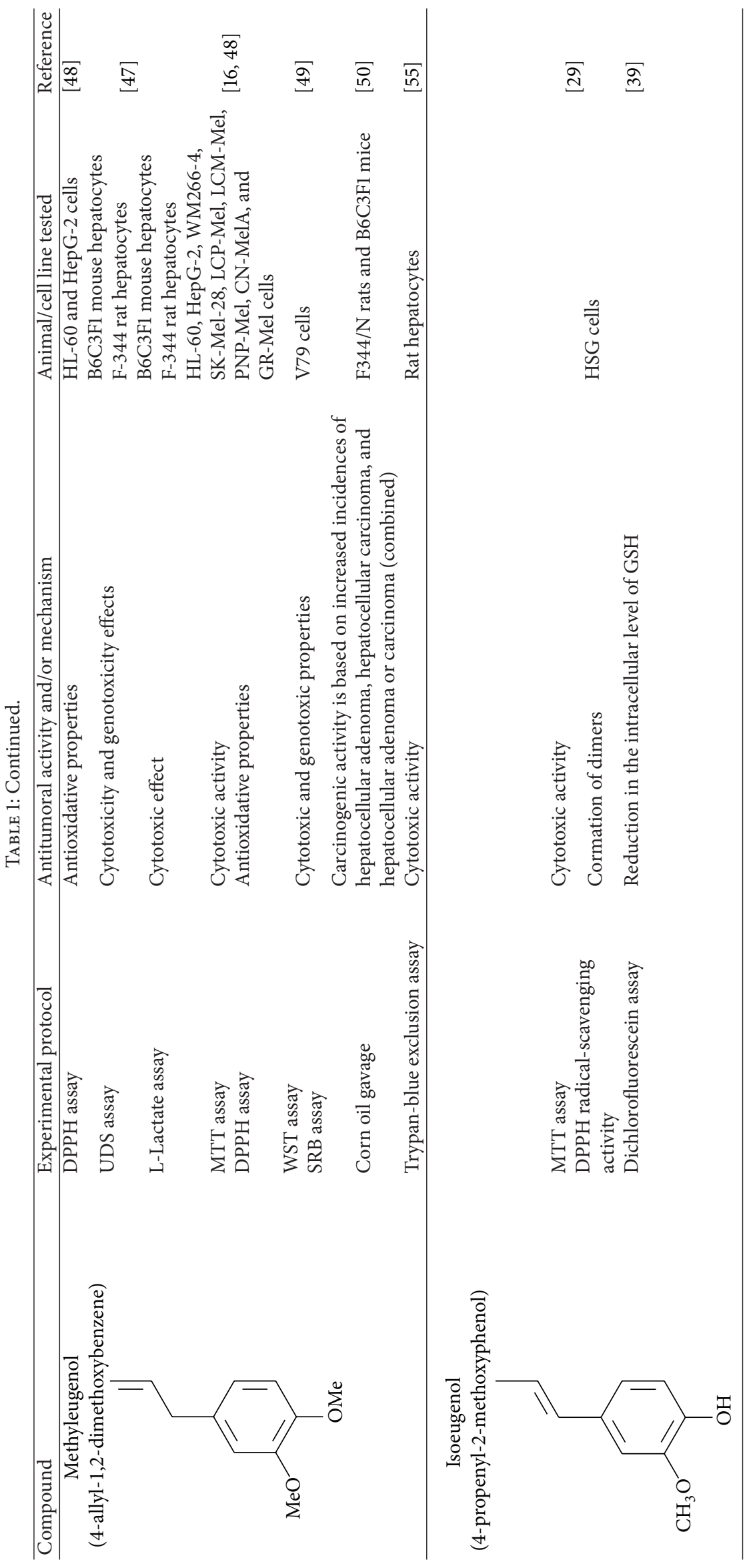




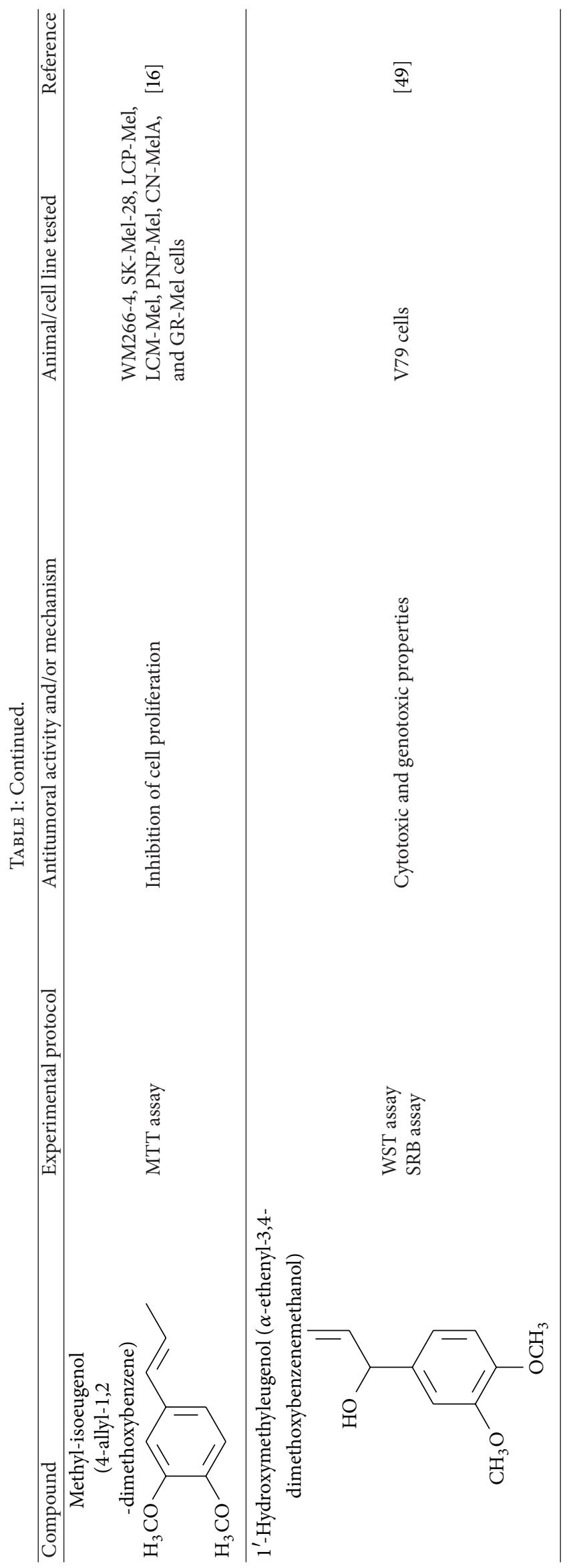




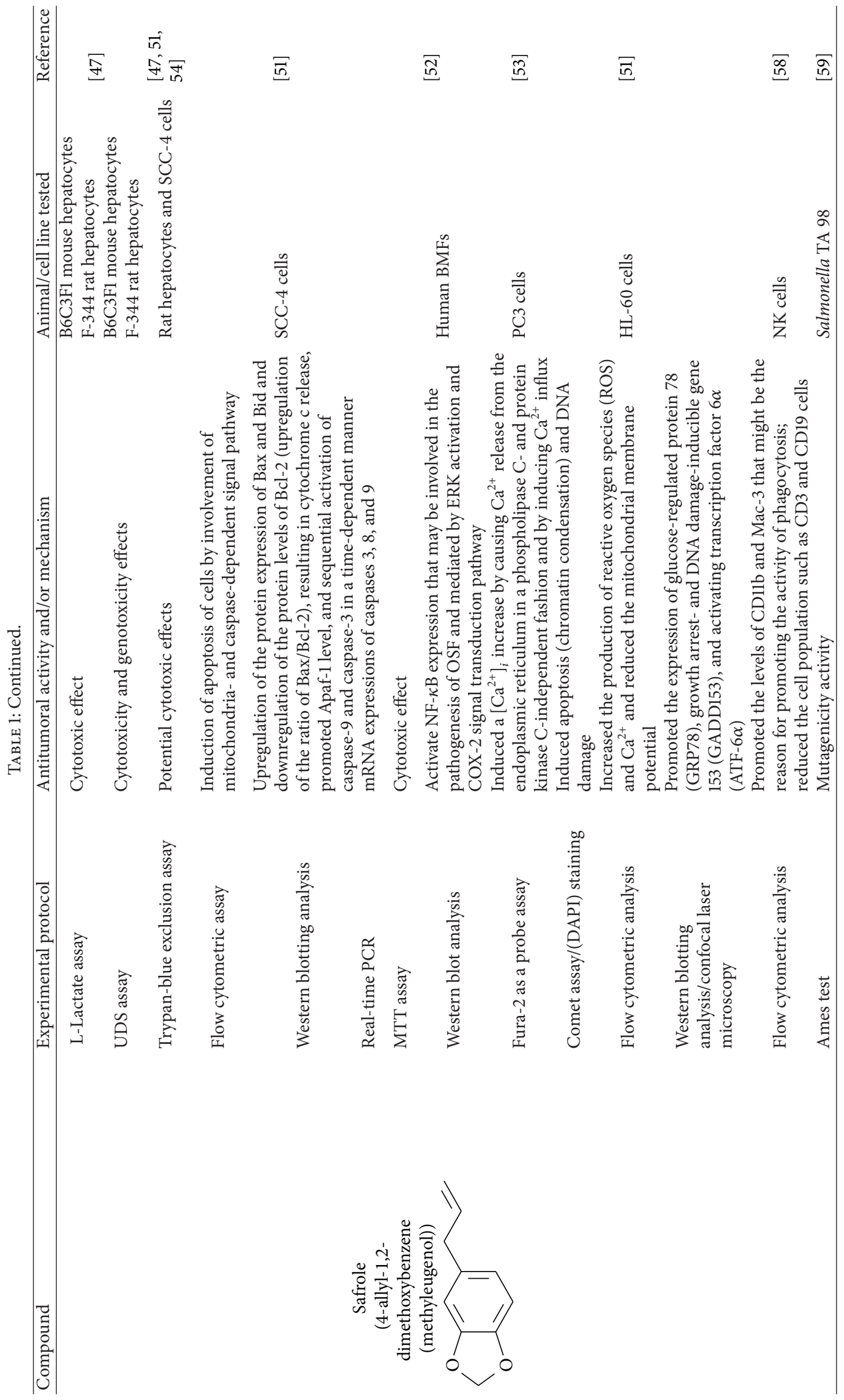




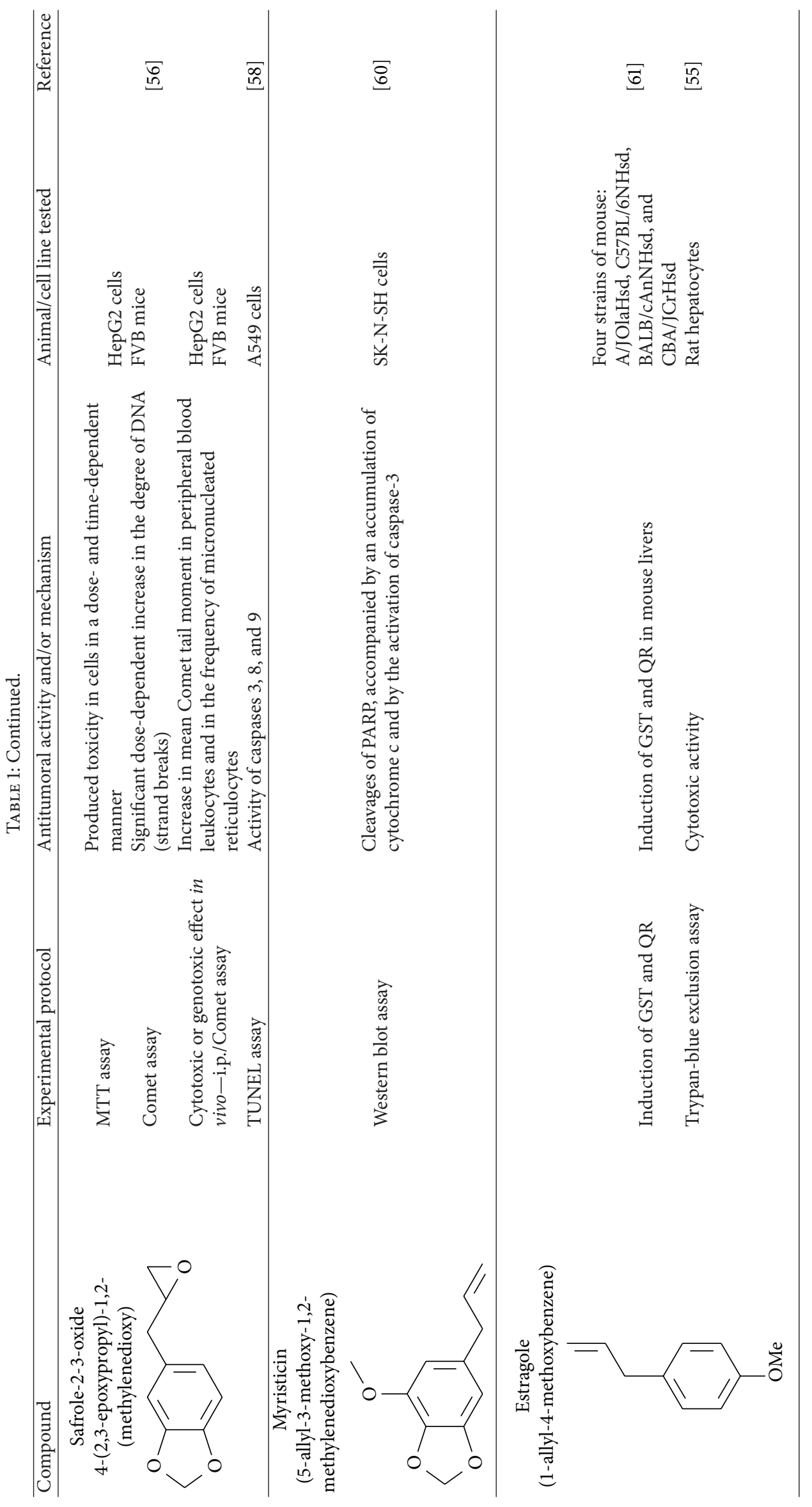




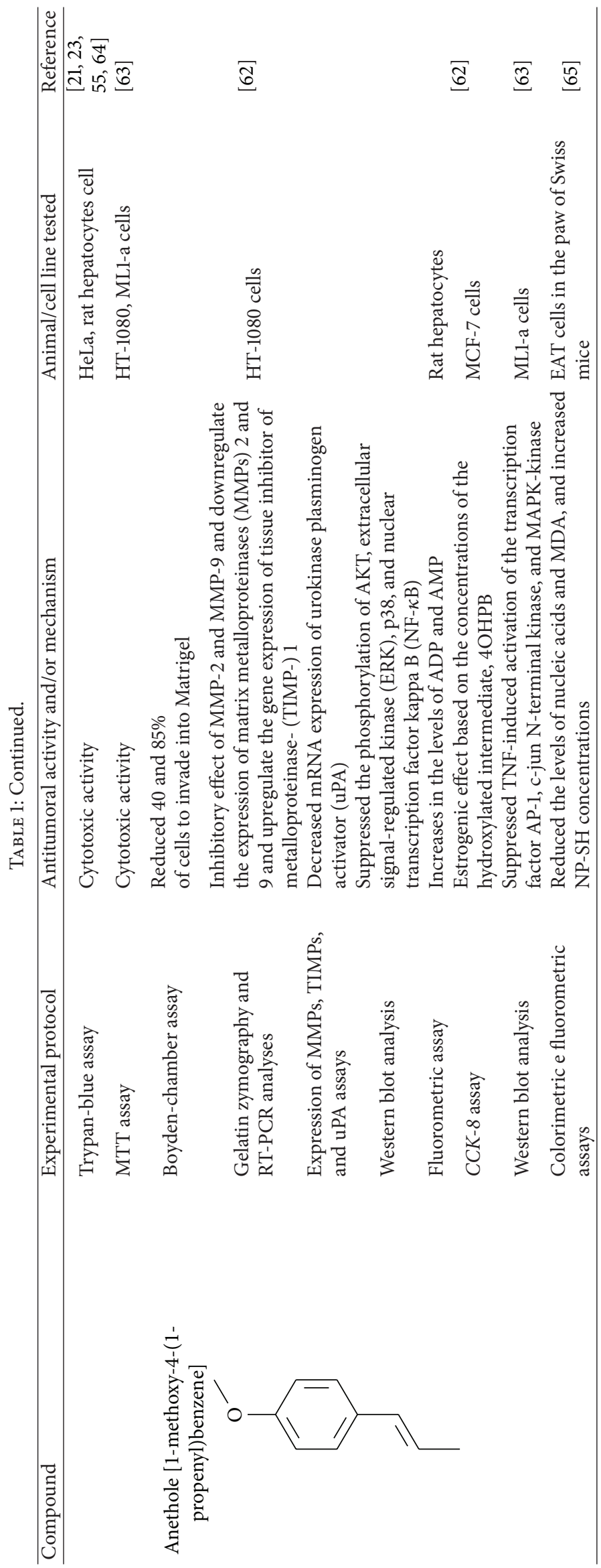




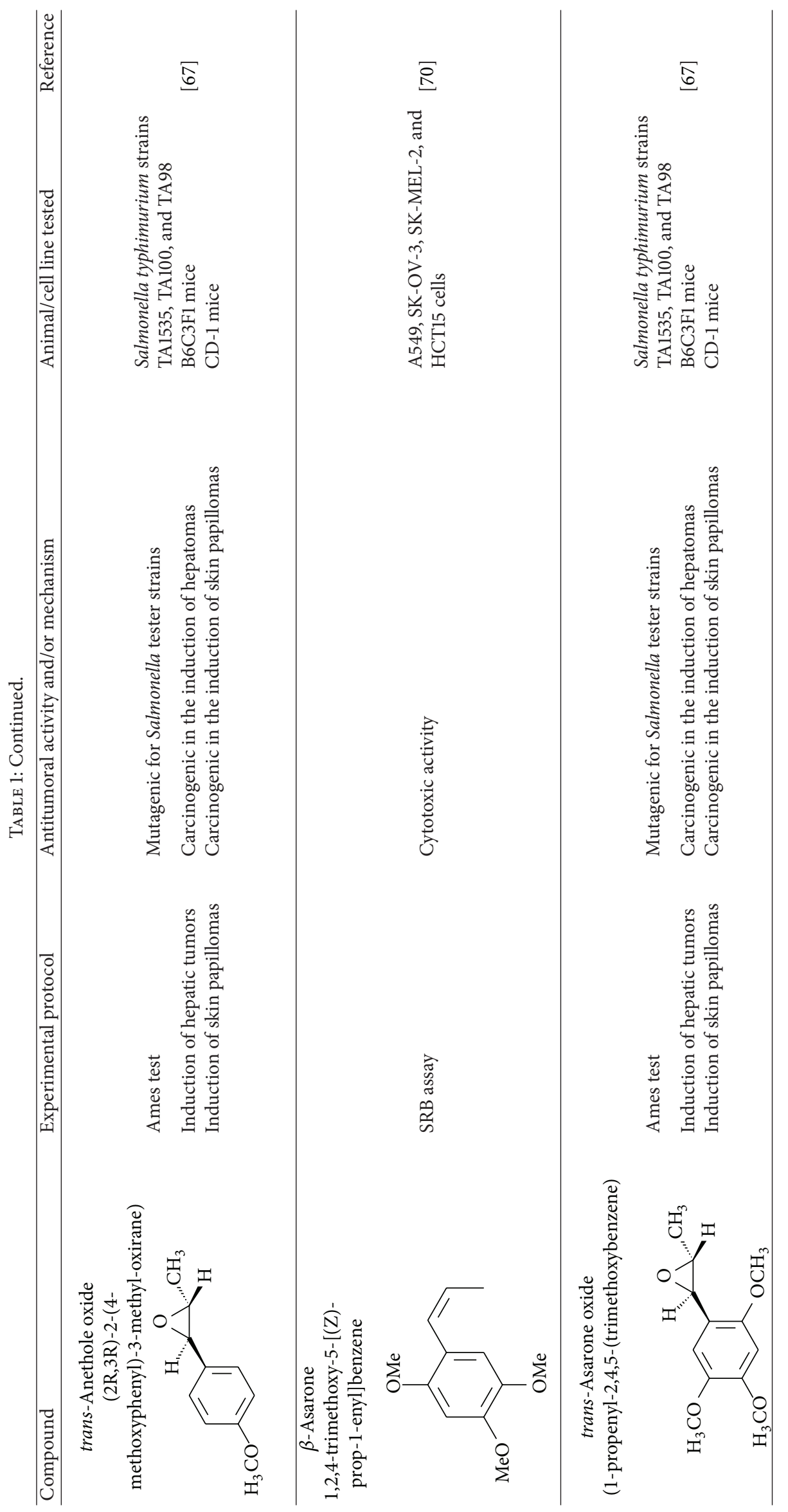




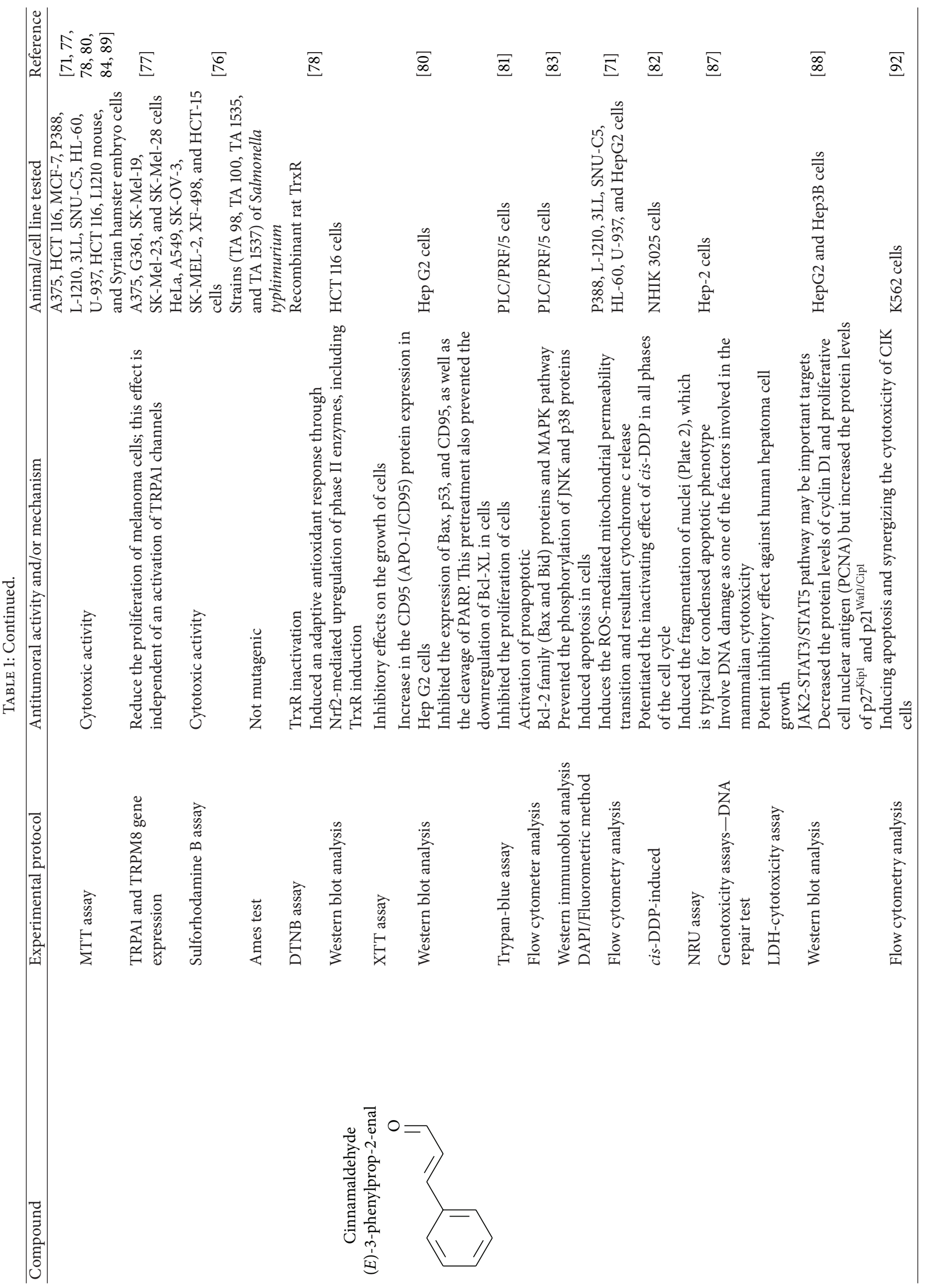




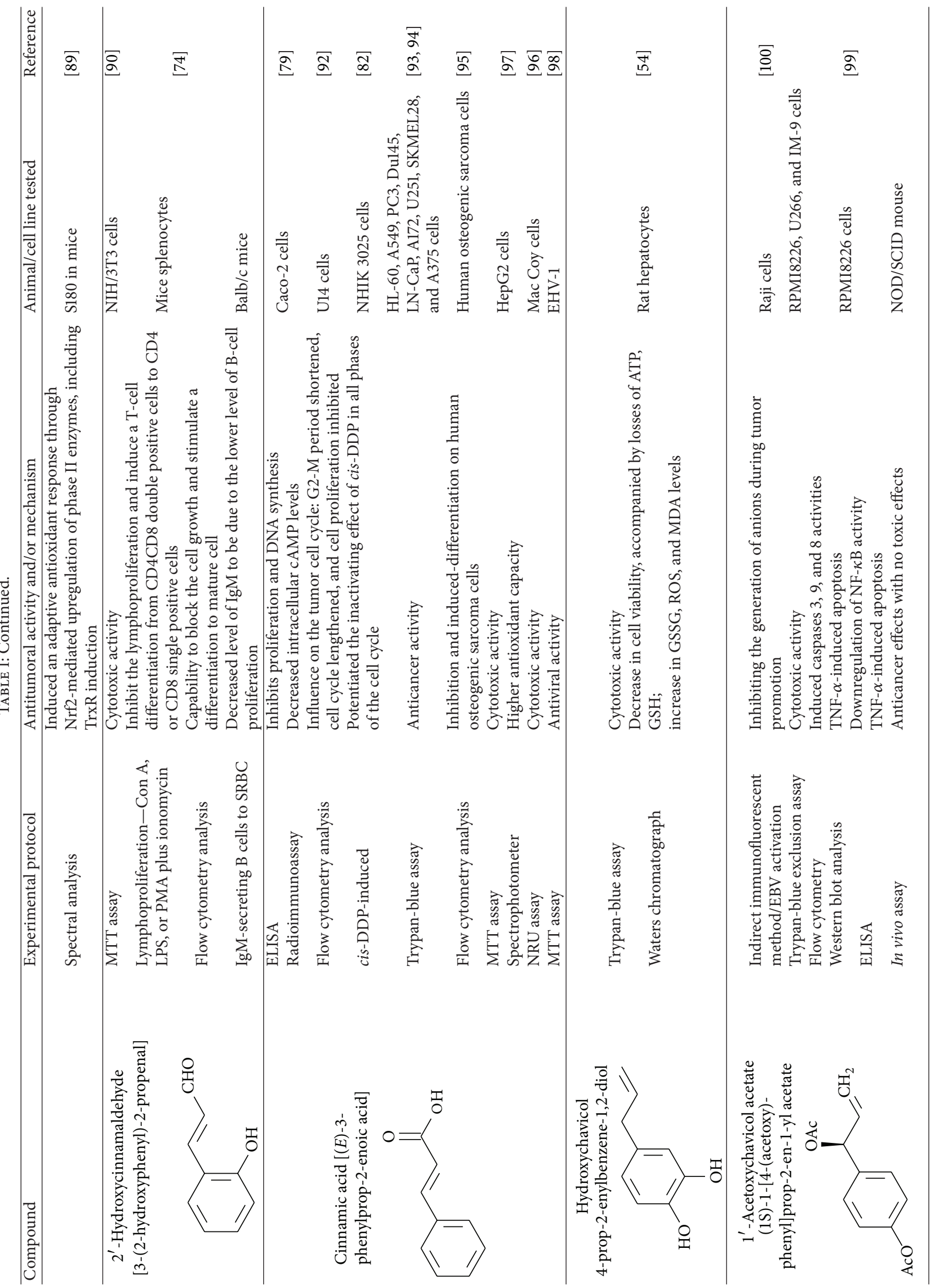


isoeugenol showed carcinogenic effects, causing increased incidence of rarely occurring thymoma and mammary gland carcinoma. There was no evidence of carcinogenic activity due to isoeugenol in female $\mathrm{F} 344 / \mathrm{N}$ rats. However, there was clear evidence of carcinogenic activity due to isoeugenol in male $\mathrm{B} 6 \mathrm{C} 3 \mathrm{~F} 1$ mice, including increased incidence of hepatocellular adenoma, hepatocellular carcinoma, and hepatocellular adenoma with carcinoma. Carcinogenic activity due to isoeugenol in female $\mathrm{B} 6 \mathrm{C} 3 \mathrm{~F} 1$ mice was observed in the form of increased incidence of histiocytic sarcoma. Exposure to isoeugenol resulted in nonneoplastic lesions of the nose in male and female rats, of the kidney in female mice, and of the nose, forestomach, and glandular stomach in mice of both sexes [50]. However, methyleugenol is minimally cytotoxic for hepatocytes and leukemia cells compared to eugenol $[48,49]$. The structural similarity of these substances with eugenol stimulates advances in pharmacological studies to explore their therapeutic potential in cancer treatment.

2.3. Safrole, Safrole-2' $2^{\prime} 3^{\prime}$-oxide, and Myristicin. Safrole is an important food-borne phytotoxin found in many natural products, such as oil of sassafras, anise, basil, nutmeg, and pepper. Safrole is cytotoxic against human tongue squamous carcinoma [51], primary human buccal mucosal fibroblasts [52], prostate cancer [53], rat hepatocytes [54], and leukemia [51] and shows genotoxic activity $[55,56]$.

Safrole induced apoptosis in human tongue squamous carcinoma SCC-4 cells by mitochondria- and caspasedependent signaling pathways. Safrole-induced apoptosis was accompanied by upregulation of Bax and Bid and downregulation of $\mathrm{Bcl}-2$, which increased the ratio of $\mathrm{Bax} / \mathrm{Bcl}-2$, resulting in cytochrome c release, increased Apaf-1 levels, and sequential activation of caspase- 9 and caspase- 3 in a timedependent manner [51]. In A549 human lung cancer cells, safrole activated caspases 3,8 , and 9 [57]. In rat hepatocytes cells, safrole induced cell death by loss of mitochondrial membrane potential and generation of oxygen radical species, which were assayed using $2^{\prime}, 7^{\prime}$-dichlorodihydrofluorescein diacetate (DCFH-DA) [54].

Fan and collaborators [58] showed that safrole promoted the activities of macrophages and NK cells in BALB/c mice. While promoting macrophage phagocytosis, safrole increased abundance of cell markers such as CD11b and Mac-3. Additionally, NK cell cytotoxicity was remarkably suppressed in mice treated with safrole, as were levels of cell markers for T cells (CD3) and B cells (CD19). Safrole was also cytotoxic against primary human buccal mucosal fibroblasts (BMFs) [52]. Ni and collaborators [52] demonstrated that safrole increased NF- $\kappa \mathrm{B}$ expression, which may have been involved in the pathogenesis of oral submucous fibrosis. NF$\kappa \mathrm{B}$ expression induced by safrole in fibroblasts may be mediated by ERK activation and the COX-2 signal transduction pathway.

A study by Chang and collaborators [53] investigated the effect of safrole on intracellular $\mathrm{Ca}^{2+}$ mobilization and viability of human PC3 prostate cancer cells. Cytosolic free $\mathrm{Ca}^{2+}$ levels $\left(\left[\mathrm{Ca}^{2+}\right]_{i}\right)$ were measured using fura-2 as a probe. Safrole increased $\left[\mathrm{Ca}^{2+}\right]_{i}$ by causing $\mathrm{Ca}^{2+}$ release from the endoplasmic reticulum in a phospholipase $\mathrm{C}$ - and protein kinase C-independent manner, which decreased cell viability in a concentration-dependent manner. In HL-60 leukemia cells, safrole promoted the expression of glucose-regulated protein 78 (GRP78), growth arrest- and DNA damageinducible gene 153 (GADD153), and activating transcription factor $6 \alpha(\mathrm{ATF}-6 \alpha)$ [51]. In the unscheduled DNA synthesis (UDS) assay described by Howes and collaborators [55], safrole exhibited genotoxic activity in freshly isolated rat hepatocyte primary cultures.

Safrole- $2^{\prime}, 3^{\prime}$-oxide (SAFO) is a reactive electrophilic metabolite of safrole. SAFO is the most mutagenic metabolite of safrole that has been tested in the Ames test, but data on the genotoxicity of SAFO in mammalian systems is scarce. SAFO induced cytotoxicity, DNA strand breakage, and micronuclei formation in human cells in vitro and in mice [56]. In addition, safrole produced mutagenicity in Salmonella TA 98 and TA 100 in the Ames test [59].

Myristicin (1-allyl-3,4-methylenedioxy-5-methoxybenzene) is an active constituent of nutmeg, parsley, and carrot. A study by Lee and collaborators [60] investigated the cytotoxic and apoptotic effects of myristicin on human neuroblastoma SK-N-SH cells. Apoptosis triggered by myristicin was caused by cleavage of PARP, which was accompanied by accumulation of cytochrome $c$ and activation of caspase- 3 . These results suggested that myristicin induced cytotoxicity in human neuroblastoma SK-N-SH cells by an apoptotic mechanism [60].

Ahmad and collaborators [61] investigated the effect of myristicin on activity of glutathione S-transferase (GST) and NADPH:quinone oxidoreductase (QR) in four mouse strains. The authors showed that activity of GST and QR was significantly increased in the livers of all four mouse strains, GST activity was increased in the intestine of three out of four strains, and QR activity was significantly increased in the lungs and stomachs of three out of four stains. Thus myristicin, which is found in a wide variety of herbs and vegetables, shows strong potential as an effective chemoprotective agent against cancer.

Safrole, safrole- $2^{\prime}, 3^{\prime}$-oxide, and myristicin are bioactive substances in antitumor models that can be used as starting materials for the preparation of derivatives with improved pharmacological profile.

2.4. Estragole, Anethole, and trans-Anethole Oxide. Estragole has been isolated from essential oils of Artemisia dracunculus and Leonotis ocymifolia. Howes and collaborators [55] demonstrated the genotoxic activity of estragole via UDS assay, in which estragole induced dose-dependent increases in UDS up to 2.7 times that of the control in rat hepatocytes in primary culture.

Anethole (1-methoxy-4-(1-propenyl)benzene) occurs naturally as a major component of essential oils from fennel and star anise and is also present in numerous plants such as dill, basil, and tarragon [62]. Anethole had a cytotoxic effect on fibrosarcoma tumor [63], breast cancer [63], hepatocytes $[55,64]$, cervical carcinoma [21, 23], and Ehrlich ascites tumor [65], as well as an anticarcinogenic effect and a lack of clastogenic potential [65]. 
Chainy and collaborators [66] reported that anethole reduced apoptosis by inhibiting induction of $\mathrm{NF}-\kappa \mathrm{B}$, activator protein 1 (AP-1), c-jun N-terminal kinase (JNK), and mitogen-activated protein kinase kinase (MAPKK) by tumor necrosis factor (TNF). Choo and collaborators investigated the antimetastatic activity of anethole [63] and showed that anethole inhibited proliferation, adhesion, and invasion of highly metastatic human HT-1080 fibrosarcoma cells. Anethole also inhibited the activity of metalloproteinases (MMP2 and MMP-9) and increased the activity of MMP inhibitor TIMP-1 [63]. Nakagawa and Suzuki [62] showed that anethole induced a concentration- and time-dependent loss of cell viability in isolated rat hepatocytes, which was followed by decreases in intracellular levels of ATP and total adenine nucleotide pools. Howes and collaborators [55] demonstrated that anethole did not induce unscheduled DNA synthesis (UDS) in rat hepatocytes in primary culture. In Ehrlich ascites tumor-bearing mice, anethole increased survival time and reduced tumor weight, tumor volume, and body weight [65].

Anethole is metabolized through 3 pathways: $O$-demethylation, $\omega$-hydroxylation followed by side chain oxidation, and epoxidation of the 1,2-double bond. The cytotoxicity of trans-anethole oxide in rat hepatocytes has been shown to be due to its metabolism to epoxide [67]. In addition, transanethole oxide produced a positive result in the Salmonella mutation assay and induced tumors in mice. These results suggest that epoxidation of the side chain of anethole in vivo could be a carcinogenic metabolic mechanism. Kim and collaborators [67] found that trans-anethole oxide is more toxic to animals than trans-anethole and was mutagenic in point mutation and frameshift mutation Ames test models. transAnethole did not induce hepatomas in male B6C3F1 mice, but the highest dose of trans-anethole oxide tested $(0.5 \mu \mathrm{mol} / \mathrm{g})$ significantly increased the incidence of hepatomas.

2.5. Asaraldehyde, $\beta$-Asarone, and trans-Asarone Oxide. Acorus gramineus (Araceae), which is distributed throughout Korea, Japan, and China, has been used in Korean traditional medicine for improvement of learning and memory, sedation, and analgesia [68]. Several pharmacologically active compounds, such as $\beta$-asarone, $\alpha$-asarone, and phenylpropenes, have been reported from this rhizome [69]. Park and collaborators [70] investigated asarone and asaraldehyde and showed minimal cytotoxicity $\left(\mathrm{IC}_{50}<30 \mu \mathrm{M}\right)$ in the SRB assay using 4 human tumor cell lines: A549 (non-small cell lung adenocarcinoma), SK-OV-3 (ovarian cancer cell), SK-MEL-2 (skin melanoma), and HCT15 (colon cancer cell). trans-Asarone oxide, prepared from trans-asarone and dimethyldioxirane, induced hepatomas in $\mathrm{B} 6 \mathrm{C} 3 \mathrm{~F} 1$ mice and skin papillomas in CD-1 mice and was mutagenic for Salmonella strains [67].

2.6. Cinnamaldehyde, $2^{\prime}$-Hydroxycinnamaldehyde, and Cinnamic Acid. Cinnamaldehyde is a bioactive compound isolated from the stem bark of Cinnamomum cassia and has been widely used in folk medicine for its anticancer [71], antibacterial [72], antimutagenic [73], and immunomodulatory effects [74], as well as to remedy other diseases [75].
The cytotoxic activity of cinnamaldehyde has been confirmed in melanoma [76, 77], the colon [76, 78, 79], breast cancer [78], hepatic tumor [80, 81], leukemia [71, 82, 83], cervical carcinoma $[76,83]$ the lung, the ovary, the central nervous system [76], lymphoma, mouse leukemia [76, 84], mouse lung carcinoma [71], lymphocytes [74], hepatocytes [85], embryo cells [86], and larynx carcinoma [87]. Its genotoxicity has been confirmed in vitro [87]. Cinnamaldehyde also had genotoxic effects against SA7-transformed Syrian hamster embryo cells [86].

$\mathrm{Ng}$ and $\mathrm{Wu}[80]$ showed that cinnamaldehyde induced lipid peroxidation in hepatocytes isolated from male SpragueDawley rats with glutathione depletion. Adding NADH generators, for example, xylitol, prevented cytotoxicity induced by cinnamaldehyde, but decreasing mitochondrial $\mathrm{NAD}^{+}$ with rotenone markedly increased cinnamaldehyde cytotoxicity. The authors showed that cinnamaldehyde-induced cytotoxicity and inhibition of mitochondrial respiration were markedly increased by ALDH inhibitors and in particular by cyanamide [80].

Chew and collaborators [78] used flow cytometric analysis to show that $80 \mu \mathrm{M}$ of cinnamaldehyde caused cell cycle arrest at the $\mathrm{G}_{2} / \mathrm{M}$ phase in HCT 116 cells and induced cleavage of caspase- 3 and PARP. It has also been proposed that cinnamaldehyde induced apoptosis by ROS release with TrxRinhibitory and Nrf2-inducing properties [78]. Ka and collaborators [71] demonstrated that cinnamaldehyde induced ROS-mediated mitochondrial permeability and cytochrome c release in human leukemia cells (HL-60).

Using hepatoma cells, Wu and collaborators [81] demonstrated that cinnamaldehyde upregulated Bax protein, downregulated Bcl-2 and $\mathrm{Mcl}-1$, and caused Bid to cleave upon the activation of caspase- 8 . These events consequently led to cell death. JNK, p38, and ERK were activated and phosphorylated after cinnamaldehyde treatment in a time-dependent manner, which suggested that apoptosis was mediated by activation of proapoptotic Bcl-2 family (Bax and Bid) proteins and MAPK pathways [81]. Cinnamaldehyde can also activate TRPA1 expression in melanoma cells [77].

Cinnamaldehyde caused a time-dependent increase in CD95 (APO-1/CD95) protein expression in HepG2 cells (human hepatoma), while also downregulating antiapoptotic proteins (Bcl-XL) and upregulating proapoptotic (Bax) proteins in a time-dependent manner [80]. Preincubation of HepG2 cells with cinnamaldehyde effectively inhibited the expression of Bax, p53, and CD95, as well as the cleavage of PARP. This pretreatment also prevented downregulation of Bcl-XL [80]. Using the HepG2 and Hep3B human hepatoma cancer cell lines, Chuang and colleagues [88] demonstrated that cinnamaldehyde had a potent inhibitory effect against human hepatoma cell growth. They observed that the JAK2STAT3/STAT5 pathway might be an important target of cinnamaldehyde. Cinnamaldehyde also altered apoptotic signaling. Cinnamaldehyde significantly decreased protein levels of cyclin D1 and proliferative cell nuclear antigen (PCNA) but increased the protein levels of $\mathrm{p} 27^{\mathrm{Kip} 1}$ and $\mathrm{p} 21^{\text {Waf1/Cip1 }}[86]$. In an assay of thioredoxin reductase (TrxR) action, cinnamaldehyde showed a TrxR inactivation effect 


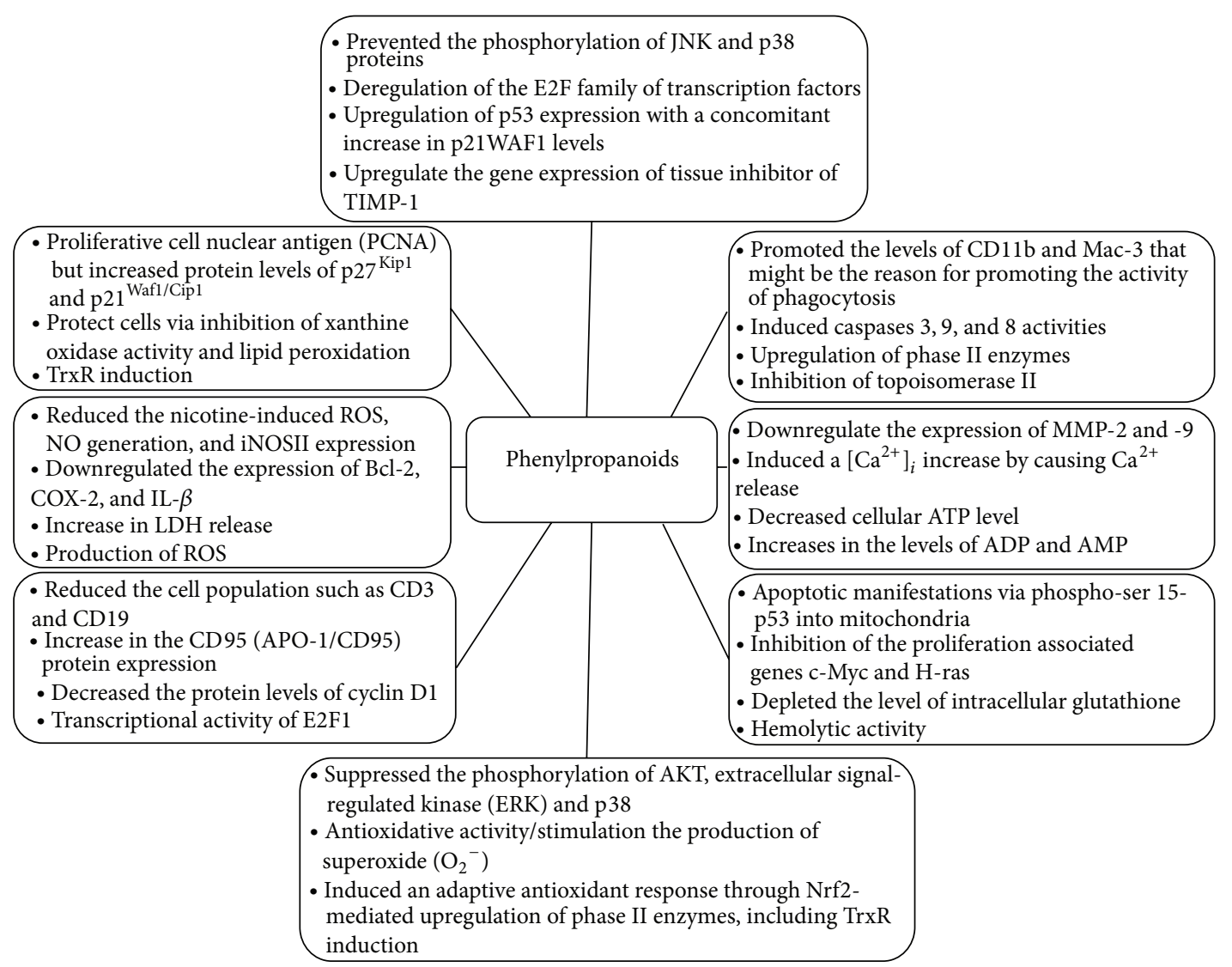

FIGURE 1: Possible mechanisms of action from phenylpropanoids antitumoral activity.

that could contribute to its cytotoxicity [89]. Furthermore, cinnamaldehyde had an antitumor effect in Sarcoma 180bearing $\mathrm{BALB} / \mathrm{c}$ mice and a protective effect on immune function [89].

$2^{\prime}$-Hydroxycinnamaldehyde, a cinnamaldehyde derivative, was studied for its immunomodulatory effects. The chemopreventive effects of cinnamaldehyde derivatives were demonstrated on hepatocellular carcinoma formation in $\mathrm{H}$ ras $12 \mathrm{~V}$ transgenic mice, where they probably produced a long-term immunostimulating effect on $\mathrm{T}$ cells, because immune cell infiltration into hepatic tissues was increased [90].

$2^{\prime}$-Hydroxycinnamaldehyde has immunomodulatory effects in vivo, but in vitro studies showed that secreted IgM level was depressed in the culture supernatants of splenocytes. Decreased IgM produced by cinnamaldehyde treatment in vitro appeared to be due to lower levels of B-cell proliferation, rather than direct inhibition of IgM production [74]. Koh and collaborators [74] also demonstrated that cinnamaldehyde induced T-cell differentiation from CD4CD8 double positive cells to CD4 or CD8 single positive cells.

Cinnamic acid occurs throughout the plant kingdom and particularly in flavor compositions and products containing cinnamon oil [91]. Cinnamic acid inhibited proliferation of uterocervical carcinoma [92], leukemia [93], colon adenocarcinoma [79], glioblastoma, melanoma, prostate, lung carcinoma [94], osteogenic sarcoma [95] cells, Mac Coy cells [96], Hep G2 cells [97], and kidney epithelial (VERO) cells [98].

Cinnamic acid had an inhibitory effect on uterocervical carcinoma (U14) cells in mice, causing tumor cell apoptosis [92]. In vitro assay of U14 cells demonstrated a shortened $\mathrm{G}_{2}-\mathrm{M}$ period, lengthened cell cycle, and inhibited cell proliferation, which supported the conclusion that cinnamic acid influenced tumor cell cycle [92].

Ekmekcioglu and collaborators [79] showed that cinnamic acid inhibited proliferation and DNA synthesis of Caco-2 (human colon) cells. Treatment with cinnamic acid modulated the Caco- 2 cell phenotype by dose-dependently stimulating sucrase and aminopeptidase $\mathrm{N}$ activity, while inhibiting alkaline phosphatase activity. In melanoma cells cinnamic acid induced cell differentiation with morphological changes and increased melanin production. Cinnamic acid reduced the invasive capacity of melanoma cells and modulated expression of genes implicated in tumor metastasis (collagenase type IV and tissue inhibitor metalloproteinase 2) and immunogenicity (HLA-A3, class-I major histocompatibility antigen) [94]. 
Using in vivo and in vitro assays, Zhang and collaborators (2010) [92] showed that cinnamic acid influenced the cell cycle of uterocervical carcinoma cells (U14); the $\mathrm{G}_{2}-\mathrm{M}$ period was shortened, cell cycle was lengthened, and cell proliferation was inhibited. Cinnamic acid also induced differentiation of human osteogenic sarcoma cells and caused a higher percentage of cells in S phase [95].

2.7. Hydroxychavicol and $1^{\prime}$-Acetoxychavicol Acetate. Hydroxychavicol (1-allyl-3,4-dihydroxybenzene) is a major component in Piper betle leaf, which is used for betel quid chewing in Asia, and is also a major metabolite of safrole, which is the main component of sassafras oil, in rats and humans. A study by Nakagawa and collaborators [54] demonstrated the biotransformation and cytotoxic effects of hydroxychavicol in freshly-isolated rat hepatocytes. In hepatocytes pretreated with diethyl maleate or salicylamide, hydroxychavicol-induced cytotoxicity was enhanced and was accompanied by a decrease in the formation of conjugates and inhibition of hydroxychavicol loss.

Other studies indicate that mitochondria are the target organelles for hydroxychavicol, which induces cytotoxicity through mitochondrial failure related to mitochondrial membrane potential at an early stage, and lipid peroxidation through oxidative stress at a later stage. Furthermore, the onset of cytotoxicity depends on the initial and residual concentrations of hydroxychavicol, rather than its metabolites.

$1^{\prime}$-Acetoxychavicol acetate is obtained from the rhizomes of Languas galanga (Zingiberaceae), a traditional condiment in Thailand. Recent studies have revealed that $1^{\prime}$ acetoxychavicol acetate has potent chemopreventive effects against rat oral carcinomas and inhibits chemically induced tumor formation and cellular growth of cancer cells. $1^{\prime}$ Acetoxychavicol acetate inhibited NF- $\kappa$ B and induced apoptosis of myeloma cells in vitro and in vivo. Therefore, $1^{\prime}$ acetoxychavicol acetate is a novel NF- $\kappa \mathrm{B}$ inhibitor and represents a new therapy for the treatment of multiple myeloma patients [99]. The isolation and identification of $1^{\prime}$ acetoxychavicol acetate, an inhibitor of xanthine oxidase, may induce antitumor activity by inhibiting generation of anions during tumor promotion [100] (Figure 1).

\section{Conclusions}

The studies presented in this review reveal the anticancer therapeutic potential of bioactive constituents found in essential oils and medicinal plants, the phenylpropanoids. The research on the clinical studies of these natural products is required to the development of new drug candidates with applications in the therapy of cancer.

\section{Abbreviations}

\section{Cell Lines}

3LL: Mouse lung carcinoma

A172: Human malignant glioblastoma

A375: Melanoma
A549: $\quad$ Lung adenocarcinoma

BMFs: Primary human buccal mucosal fibroblasts

Caco-2: Human colon adenocarcinoma

CD11b: Monocytes

CD19: B cells

CD3: $\quad$ T cells

CEM: $\quad$ Acute T lymphoblastoid leukemia

CN-Mel: Melanoma

DU-145: Androgen-insensitive prostate cancer

F344: Hepatocytes

G361: Melanoma

GR-Mel: Melanoma

HCT-15: Colon tumor

HeLa: Human cervical carcinoma

Hep3B: Human hepatoma cancer

HepG2: Human hepatoma

HGF: Human gingival fibroblasts

HL-60: Human promyelocytic leukemia

HSC-3: Human oral cancer cells

HSG: Human submandibular gland carcinoma

HT-1080: Human fibrosarcoma tumor

K-562: Human chronic myelogenous leukemia

KB: $\quad$ Oral squamous carcinoma

L-1210: $\quad$ Mouse leukemia

LCM-Mel: Melanoma

LCP-Mel: Melanoma

LN-CaP: Prostate cancer

Mac-3: $\quad$ Macrophages

MCF-7 gem: Human breast adenocarcinoma (resistant to gemcitabine)

MCF-7: Human breast adenocarcinoma

ML-1: Human myeloblastic leukemia

NHIK 3025: Human cervical carcinoma

P388: $\quad$ Mouse leukemia

P-815: $\quad$ Murine mastocytoma

PC-3: Human prostate cancer

PLC/PRF/5: Human hepatoma

PNP-Mel: Melanoma

Raw 264.7: Mouse leukemic monocyte macrophage

S180: $\quad$ Sarcoma 180

SbCl2: $\quad$ Primary melanoma

SCC-4: Tongue squamous carcinoma

SK-Mel-19: Melanoma

SK-MEL-2: Skin melanoma

SK-MEL-23: Melanoma

SK-MEL-28: Melanoma

SK-N-SH: Neuroblastoma

SK-OV-3: Ovarian cancer

SNU-C5: Human colon cancer

U14: Uterocervical carcinoma

U251: Human malignant glioblastoma

U-937: $\quad$ Human histiocytic lymphoma

uPA: Urokinase plasminogen activator

WM1205Lu: Metastatic melanoma

WM266-4: Melanoma 
WM3211: Primary radial growth phase melanoma

WM98-1: Primary vertical growth phase melanoma

XF-498: Central nerve system.

Tests

AFC:

ALDH:

Ames test:

Antibody forming cell

Aldehyde dehydrogenase

Biological assay to assess the

mutagenic potential of chemical compounds

Boyden-chamber assay: Evaluation of tumor cell invasion in vitro

c-AMP:

Cyclic adenosine

CAs:

CCK-8:

CDFHDA:

Comet assay:

Con A:

DAPI:

DCFH:

DEM:

DMBA:

DPPH:

DTNB:

EBV:

EHV-1:

ESR:

GSSG:

GST:

LDH:

LPS:

MDA:

MMP:

MTT:

NF- $\kappa \mathrm{B}$ :

NRU assay:

p21WAF1:

PARP:

PBS:

PCR:

PMA:

QR:

SRB:

SRBC:

TBA: monophosphate

Chromosomal aberrations

Cell Counting Kit-8, a sensitive colorimetric assay

5-(and -6)-carboxy-2', $7^{\prime}$ -

dichlorofluorescein

diacetate

Single-cell gel electrophoresis

Concanavalin

4',6-Diamidino-2-phenylindole

Dichlorofluorescein

Diethyl maleate

7,12-Dimethylbenz[a] anthracene

1,1-Diphenyl-2-picrylhydrazyl

5,5'-Dithiobis-(2-nitrobenzoic acid)

Epstein-Barr virus

Herpes virus 1

Electron spin resonance

spectroscopy

Oxidized glutathione

Glutathione S-transferase

Lactate dehydrogenase

Lipopolysaccharide

Malondialdehyde

Matrix metalloproteinase

[3(4,5-Dimethyl-thiazol-2-yl)-

2,5-diphenyl tetrazolium

bromide]

Nuclear factor-kappa B

Neutral red uptake

Cyclin-dependent kinase

inhibitor CDKN1A

Poly(ADP-ribose) polymerase

Phosphate-buffered saline

Polymerase chain reaction

Phorbol 12-myristate-13-acetate

plus ionomycin

Quinone oxidoreductase

Sulforhodamine B

Sheep red blood cells

Test in the aqueous phase
TBARS: Thiobarbituric acid reactive substances

TUNEL: $\quad$ Terminal deoxynucleotidyl transferase-mediated dUTP nick end-labeling

UDS assay: Unscheduled DNA synthesis

V-FITC assay: Apoptosis detection kit

WST: Tetrazolium salt

XTT: 2,3-Bis-(2-methoxy-4-nitro-5-

sulfophenyl)-2H-tetrazolium-5-

carboxanilide.

\section{Conflict of Interests}

The authors declare no conflict of interests.

\section{Acknowledgments}

This research was supported by Conselho Nacional de Desenvolvimento Científico e Tecnológico (CNPq) and Coordenação de Aperfeiçoamento de Pessoal de Nível Superior (CAPES).

\section{References}

[1] D. Hanahan and R. A. Weinberg, "The hallmarks of cancer," Cell, vol. 100, no. 1, pp. 57-70, 2000.

[2] D. P. de Sousa, "Analgesic-like activity of essential oils constituents," Molecules, vol. 16, no. 3, pp. 2233-2252, 2011.

[3] R. N. de Almeida, M. de Fátima Agra, F. N. S. Maior, and D. P. de Sousa, "Essential oils and their constituents: anticonvulsant activity," Molecules, vol. 16, no. 3, pp. 2726-2742, 2011.

[4] R. D. C. Da Silveira E Sá, L. N. Andrade, R. D. R. B. De Oliveira, and D. P. De Sousa, "A review on anti-inflammatory activity of phenylpropanoids found in essential oils," Molecules, vol. 19, no. 2, pp. 1459-1480, 2014.

[5] Y.-C. Su and C.-L. Ho, "Composition, in-vitro anticancer, and antimicrobial activities of the leaf essential oil of Machilus mushaensis from Taiwan," Natural Product Communications, vol. 8, no. 2, pp. 273-275, 2013.

[6] A. Manjamalai and V. M. B. Grace, "The chemotherapeutic effect of essential oil of Plectranthus amboinicus (Lour) on lung metastasis developed by B16F-10 cell line in C57BL/6 mice," Cancer Investigation, vol. 31, no. 1, pp. 74-82, 2013.

[7] H. M. Ashour, "Antibacterial, antifungal, and anticancer activities of volatile oils and extracts from stems, leaves, and flowers of Eucalyptus sideroxylon and Eucalyptus torquata," Cancer Biology and Therapy, vol. 7, no. 3, pp. 399-403, 2008.

[8] A. L. Medina-Holguín, F. Omar Holguín, S. Micheletto, S. Goehle, J. A. Simon, and M. A. O'Connell, "Chemotypic variation of essential oils in the medicinal plant, Anemopsis californica," Phytochemistry, vol. 69, no. 4, pp. 919-927, 2008.

[9] P. Kathirvel and S. Ravi, "Chemical composition of the essential oil from basil (Ocimum basilicum Linn.) and its in vitro cytotoxicity against HeLa and HEp-2 human cancer cell lines and NIH 3 T3 mouse embryonic fibroblasts," Natural Product Research, vol. 26, no. 12, pp. 1112-1118, 2012.

[10] D. Pal, S. Banerjee, S. Mukherjee, A. Roy, C. K. Panda, and S. Das, "Eugenol restricts DMBA croton oil induced skin 
carcinogenesis in mice: downregulation of c-Myc and H-ras, and activation of p53 dependent apoptotic pathway," Journal of Dermatological Science, vol. 59, pp. 31-39, 2010.

[11] B. S. Park, Y. S. Song, S.-B. Yee et al., "Phospho-ser 15-p53 translocates into mitochondria and interacts with Bcl-2 and BclxL in eugenol-induced apoptosis," Apoptosis, vol. 10, no. 1, pp. 193-200, 2005.

[12] S. K. Jaganathan and E. Supriyanto, "Antiproliferative and molecular mechanism of eugenol-induced apoptosis in cancer cells," Molecules, vol. 17, no. 6, pp. 6290-6304, 2012.

[13] A. Jaafari, M. Tilaoui, H. A. Mouse et al., "Comparative study of the antitumor effect of natural monoterpenes: relationship to cell cycle analysis," Brazilian Journal of Pharmacognosy, vol. 22, no. 3, pp. 534-540, 2012.

[14] H. Satooka and I. Kubo, "Effects of eugenol on murine B16F10 melanoma cells," in Proceedings of the 238th ACS National Meeting, pp. 16-20, Washington, DC, USA, 2009.

[15] R. Ghosh, N. Nadiminty, J. E. Fitzpatrick, W. L. Alworth, T. J. Slaga, and A. P. Kumar, "Eugenol causes melanoma growth suppression through inhibition of E2F1 transcriptional activity," Journal of Biological Chemistry, vol. 280, no. 7, pp. 5812-5819, 2005.

[16] M. Pisano, G. Pagnan, M. Loi et al., "Antiproliferative and proapoptotic activity of eugenol-related biphenyls on malignant melanoma cells," Molecular Cancer, vol. 6, article 8, 2007.

[17] S. Fujisawa, T. Atsumi, K. Satoh et al., "Radical generation, radical-scavenging activity, and cytotoxicity of eugenol-related compounds," In Vitro and Molecular Toxicology, vol. 13, no. 4, pp. 269-279, 2000.

[18] D. Slameňová, E. Horváthová, L. Wsólová, M. Šramková, and J. Navarová, "Investigation of anti-oxidative, cytotoxic, DNA-damaging and DNA-protective effects of plant volatiles eugenol and borneol in human-derived HepG2, Caco-2 and VH10 cell lines," Mutation Research-Genetic Toxicology and Environmental Mutagenesis, vol. 677, no. 1-2, pp. 46-52, 2009.

[19] S. Hemaiswarya and M. Doble, "Combination of phenylpropanoids with 5-fluorouracil as anti-cancer agents against human cervical cancer (HeLa) cell line," Phytomedicine, vol. 20, no. 2, pp. 151-158, 2013.

[20] A. Hussain, K. Brahmbhatt, A. Priyani, M. Ahmed, T. A. Rizvi, and C. Sharma, "Eugenol enhances the chemotherapeutic potential of gemcitabine and induces anticarcinogenic and antiinflammatory activity in human cervical cancer cells," Cancer Biotherapy and Radiopharmaceuticals, vol. 26, no. 5, pp. 519-527, 2011.

[21] S. Stoichev, G. Zolotovich, C. Nachev, and K. Silyanovska, "Cytotoxic effect of phenols, phenol ethers, furan derivatives, and oxides isolated from essential oils," Comptes Rendus de l'Academie Bulgare des Sciences, vol. 20, pp. 1341-1344, 1967.

[22] P. Zhang, E. Zhang, M. Xiao, C. Chen, and W. Xu, "Enhanced chemical and biological activities of a newly biosynthesized eugenol glycoconjugate, eugenol $\alpha$-d-glucopyranoside," Applied Microbiology and Biotechnology, vol. 97, no. 3, pp. 1043-1050, 2013.

[23] G. Zolotovich, K. Silyanovska, S. Stoichev, and C. Nachev, "Cytotoxic effect of essential oils and their individual components. II. Oxygen-containing compounds excluding alcohols," Parfuemerie und Kosmetik, vol. 50, pp. 257-260, 1969.

[24] R. Ghosh, M. Ganapathy, W. L. Alworth, D. C. Chan, and A. P. Kumar, "Combination of 2-methoxyestradiol $\left(2-\mathrm{ME}_{2}\right)$ and eugenol for apoptosis induction synergistically in androgen independent prostate cancer cells," The Journal of Steroid Biochemistry and Molecular Biology, vol. 113, no. 1-2, pp. 25-35, 2009.

[25] S. Fujisawa, T. Atsumi, M. Ishihara, and Y. Kadoma, "Cytotoxicity, ROS-generation activity and radical-scavenging activity of curcumin and related compounds," Anticancer Research, vol. 24, no. 2, pp. 563-569, 2004.

[26] G. Awuti, G. Tuerxun, A. Tuerxun, and J. Tuerxun, "Cytotoxicity of two different pulp capping materials on human dental pulp cells in vitro," Journal of Oral Science Research, vol. 28, no. 5, pp. 485-487, 2012.

[27] S. K. Mahapatra, S. Bhattacharjee, S. P. Chakraborty, S. Majumdar, and S. Roy, "Alteration of immune functions and Th1/Th2 cytokine balance in nicotine-induced murine macrophages: immunomodulatory role of eugenol and $\mathrm{N}$-acetylcysteine," International Immunopharmacology, vol. 11, no. 4, pp. 485-495, 2011.

[28] A. H. Carrasco, C. L. Espinoza, V. Cardile et al., "Eugenol and its synthetic analogues inhibit cell growth of human cancer cells (Part I)," Journal of the Brazilian Chemical Society, vol. 19, no. 3, pp. 543-548, 2008.

[29] S. Fujisawa, T. Atsumi, Y. Kadoma, and H. Sakagami, "Antioxidant and prooxidant action of eugenol-related compounds and their cytotoxicity," Toxicology, vol. 177, no. 1, pp. 39-54, 2002.

[30] K. Satoh, Y. Ida, H. Sakagami, T. Tanaka, and S. Fujisawa, "Effect of antioxidants on radical intensity and cytotoxic activity of eugenol," Anticancer Research, vol. 18, no. 3 A, pp. 1549-1552, 1998.

[31] Y. Kashiwagi, "A cytotoxic study of eugenol and its ortho dimer (bis-eugenol)," Meikai Daigaku Shigaku Zasshi, vol. 29, pp. 176188, 2001.

[32] R. Gerosa, M. Borin, G. Menegazzi, M. Puttini, and G. Cavalleri, "In vitro evaluation of the cytotoxicity of pure eugenol," Journal of Endodontics, vol. 22, no. 10, pp. 532-534, 1996.

[33] J. H. Jeng, L. J. Hahn, F. J. Lu, Y. J. Wang, and M. Y. Kuo, “Eugenol triggers different pathobiological effects on human oral mucosal fibroblasts," Journal of Dental Research, vol. 73, no. 5, pp. 10501055, 1994.

[34] H. Babich, A. Stern, and E. Borenfreund, "Eugenol cytotoxicity evaluated with continuous cell lines," Toxicology in Vitro, vol. 7, no. 2, pp. 105-109, 1993.

[35] M. Anpo, K. Shirayama, and T. Tsutsui, "Cytotoxic effect of eugenol on the expression of molecular markers related to the osteogenic differentiation of human dental pulp cells," Odontology, vol. 99, no. 2, pp. 188-192, 2011.

[36] T. Atsumi, I. Iwakura, S. Fujisawa, and T. Ueha, "Reactive oxygen species generation and photo-cytotoxicity of eugenol in solutions of various pH," Biomaterials, vol. 22, no. 12, pp. 14591466, 2001.

[37] T. Atsumi, S. Fujisawa, K. Satoh et al., "Cytotoxicity and radical intensity of eugenol, isoeugenol or related dimers," Anticancer Research, vol. 20, no. 4, pp. 2519-2524, 2000.

[38] A. Hussain, A. Priyani, L. Sadrieh, K. Brahmbhatt, M. Ahmed, and C. Sharma, "Concurrent sulforaphane and eugenol induces differential effects on human cervical cancer cells," Integrative Cancer Therapies, vol. 11, no. 2, pp. 154-165, 2012.

[39] T. Atsumi, S. Fujisawa, and K. Tonosaki, "A comparative study of the antioxidant/prooxidant activities of eugenol and isoeugenol with various concentrations and oxidation conditions," Toxicology in Vitro, vol. 19, no. 8, pp. 1025-1033, 2005. 
[40] Y. Suzuki, K. Sugiyama, and H. Furuta, "Eugenol-mediated superoxide generation and cytotoxicity in guinea pig neutrophils," Japanese Journal of Pharmacology, vol. 39, no. 3, pp. 381-386, 1985.

[41] A. Maralhas, A. Monteiro, C. Martins et al., "Genotoxicity and endoreduplication inducing activity of the food flavouring eugenol," Mutagenesis, vol. 21, no. 3, pp. 199-204, 2006.

[42] G. Kaur, M. Athar, and M. Sarwar Alam, "Eugenol precludes cutaneous chemical carcinogenesis in mouse by preventing oxidative stress and inflammation and by inducing apoptosis," Molecular Carcinogenesis, vol. 49, no. 3, pp. 290-301, 2010.

[43] T. Ogiwara, K. Satoh, Y. Kadoma et al., "Radical scavenging activity and cytotoxicity of ferulic acid," Anticancer Research, vol. 22, no. 5, pp. 2711-2717, 2002.

[44] S. K. Jaganathan, D. Mondhe, Z. A. Wani, H. C. Pal, and M. Mandal, "Effect of honey and eugenol on ehrlich ascites and solid carcinoma," Journal of Biomedicine and Biotechnology, vol. 2010, Article ID 989163, 5 pages, 2010.

[45] E. Tangke Arung, E. Matsubara, I. Wijaya Kusuma, E. Sukaton, K. Shimizu, and R. Kondo, "Inhibitory components from the buds of clove (Syzygium aromaticum) on melanin formation in B16 melanoma cells," Fitoterapia, vol. 82, no. 2, pp. 198-202, 2011.

[46] C. M. Marya, G. Satija, J. Avinash, R. Nagpal, R. Kapoor, and A. Ahmad, "In vitro inhibitory effect of clove essential oil and its two active principles on tooth decalcification by apple juice," International Journal of Dentistry, vol. 2012, Article ID 759618, 6 pages, 2012.

[47] J. L. Burkey, J.-M. Sauer, C. A. McQueen, and I. G. Sipes, "Cytotoxicity and genotoxicity of methyleugenol and related congeners-a mechanism of activation for methyleugenol," Mutation Research: Fundamental and Molecular Mechanisms of Mutagenesis, vol. 453, no. 1, pp. 25-33, 2000.

[48] K.-T. Lee, J. Choi, J.-H. Park, W.-T. Jung, H.-J. Jung, and H.J. Park, "Composition of the essential oil of Chrysanthemum sibiricum, and cytotoxic properties," Natural Product Sciences, vol. 8, no. 4, pp. 133-136, 2002.

[49] I. A. Maria Groh, A. T. Cartus, S. Vallicotti et al., "Genotoxic potential of methyleugenol and selected methyleugenol metabolites in cultured Chinese hamster V79 cells," Food and Function, vol. 3, no. 4, pp. 428-436, 2012.

[50] National Toxicology Program, “Toxicology and carcinogenesis studies of isoeugenol (CAS No. 97-54-1) in F344/N rats and B6C3F1 mice (gavage studies)," National Toxicology Program Technical Report Series, vol. 551, pp. 1-178, 2010.

[51] F.-S. Yu, A.-C. Huang, J.-S. Yang et al., "Safrole induces cell death in human tongue squamous cancer SCC-4 cells through mitochondria-dependent caspase activation cascade apoptotic signaling pathways," Environmental Toxicology, vol. 27, no. 7, pp. 433-444, 2012.

[52] W.-F. Ni, C.-H. Tsai, S.-F. Yang, and Y.-C. Chang, "Elevated expression of NF- $\kappa \mathrm{B}$ in oral submucous fibrosis-evidence for NF- $\kappa \mathrm{B}$ induction by safrole in human buccal mucosal fibroblasts," Oral Oncology, vol. 43, no. 6, pp. 557-562, 2007.

[53] H. C. Chang, H. H. Cheng, C. J. Huang et al., "Safrole-induced $\mathrm{Ca}^{2+}$ mobilization and cytotoxicity in human PC3 prostate cancer cells," Journal of Receptors and Signal Transduction, vol. 26, no. 3, pp. 199-212, 2006.

[54] Y. Nakagawa, T. Suzuki, K. Nakajima, H. Ishii, and A. Ogata, "Biotransformation and cytotoxic effects of hydroxychavicol, an intermediate of safrole metabolism, in isolated rat hepatocytes," Chemico-Biological Interactions, vol. 180, no. 1, pp. 89-97, 2009.
[55] A. J. Howes, V. S. W. Chan, and J. Caldwell, "Structurespecificity of the genotoxicity of some naturally occurring alkenylbenzenes determined by the unscheduled DNA synthesis assay in rat hepatocytes," Food and Chemical Toxicology, vol. 28, no. 8, pp. 537-542, 1990.

[56] S.-Y. Chiang, P.-Y. Lee, M.-T. Lai et al., "Safrole- $2^{\prime}, 3^{\prime}$-oxide induces cytotoxic and genotoxic effects in HepG2 cells and in mice," Mutation Research-Genetic Toxicology and Environmental Mutagenesis, vol. 726, no. 2, pp. 234-241, 2011.

[57] A. Du, B. Zhao, D. Yin, S. Zhang, and J. Miao, "Safrole oxide induces apoptosis by activating caspase-3, -8, and -9 in A549 human lung cancer cells," Bioorganic and Medicinal Chemistry Letters, vol. 16, no. 1, pp. 81-83, 2006.

[58] M.-J. Fan, S.-Y. Lin, C.-C. Yu et al., "Safrole-modulated immune response is mediated through enhancing the CD1lb surface marker and stimulating the phagocytosis by macrophages in BALB/c mice," Human \& Experimental Toxicology, vol. 31, no. 9, pp. 898-904, 2012.

[59] S. E. A. Farag and M. A. A. Abo-Zeid, "Mutagenicity and degradation of natural carcinogenic compound-safrole in spices under different processing methods," Journal of Pharmaceutical Sciences, vol. 17, pp. 149-158, 1996.

[60] B. K. Lee, J. H. Kim, J. W. Jung et al., "Myristicin-induced neurotoxicity in human neuroblastoma SK-N-SH cells," Toxicology Letters, vol. 157, no. 1, pp. 49-56, 2005.

[61] H. Ahmad, V. Valdivia, A. Cadena et al., "Myristicin: inducer of phase-II drug metabolizing enzymes and prospective chemoprotective agent against cancer," Acta Horticulturae, vol. 841, pp. 47-54, 2009.

[62] Y. Nakagawa and T. Suzuki, "Cytotoxic and xenoestrogenic effects via biotransformation of trans-anethole on isolated rat hepatocytes and cultured MCF-7 human breast cancer cells," Biochemical Pharmacology, vol. 66, no. 1, pp. 63-73, 2003.

[63] E. J. Choo, Y.-H. Rhee, S.-J. Jeong et al., "Anethole exerts antimetatstaic activity via inhibition of matrix metalloproteinase 2/9 and AKT/mitogen-activated kinase/nuclear factor kappa B signaling pathways," Biological and Pharmaceutical Bulletin, vol. 34, no. 1, pp. 41-46, 2011.

[64] A. D. Marshall and J. Caldwell, "Influence of modulators of epoxide metabolism on the cytotoxicity of trans-anethole in freshly isolated rat hepatocytes," Food and Chemical Toxicology, vol. 30, no. 6, pp. 467-473, 1992.

[65] M. M. Al-Harbi, S. Qureshi, M. Raza, M. M. Ahmed, A. B. Giangreco, and A. H. Shah, "Influence of anethole treatment on the tumour induced by Ehrlich ascites carcinoma cells in paw of Swiss albino mice," European Journal of Cancer Prevention, vol. 4, no. 4, pp. 307-318, 1995.

[66] G. B. N. Chainy, S. K. Manna, M. M. Chaturvedi, and B. B. Aggarwal, "Anethole blocks both early and late cellular responses transduced by tumor necrosis factor: effect on NF$\kappa \mathrm{B}, \mathrm{AP}-1, \mathrm{JNK}, \mathrm{MAPKK}$ and apoptosis," Oncogene, vol. 19, no. 25, pp. 2943-2950, 2000.

[67] S. G. Kim, A. Liem, B. C. Stewart, and J. A. Miller, "New studies on trans-anethole oxide and trans-asarone oxide," Carcinogenesis, vol. 20, no. 7, pp. 1303-1307, 1999.

[68] J.-F. Liao, S.-Y. Huang, Y.-M. Jan, L.-L. Yu, and C.-F. Chen, "Central inhibitory effects of water extract of Acori graminei rhizoma in mice," Journal of Ethnopharmacology, vol. 61, no. 3, pp. 185-193, 1998. 
[69] M. D. Greca, P. Monaco, L. Previtera, G. Aliotta, G. Pinto, and A. Pollio, "Allelochemical activity of phenylpropanes from Acorus gramineus," Phytochemistry, vol. 28, no. 9, pp. 2319-2321, 1989.

[70] C. H. Park, K. H. Kim, I. K. Lee et al., "Phenolic constituents of Acorus gramineus," Archives of Pharmacal Research, vol. 34, no. 8, pp. 1289-1296, 2011.

[71] H. Ka, H.-J. Park, H.-J. Jung et al., "Cinnamaldehyde induces apoptosis by ROS-mediated mitochondrial permeability transition in human promyelocytic leukemia HL-60 cells," Cancer Letters, vol. 196, no. 2, pp. 143-152, 2003.

[72] S.-T. Chang, P.-F. Chen, and S.-C. Chang, "Antibacterial activity of leaf essential oils and their constituents from Cinnamomum osmophloeum," Journal of Ethnopharmacology, vol. 77, no. 1, pp. 123-127, 2001.

[73] D. T. Shaughnessy, R. W. Setzer, and D. M. DeMarini, "The antimutagenic effect of vanillin and cinnamaldehyde on spontaneous mutation in Salmonella TA104 is due to a reduction in mutations at GC but not AT sites," Mutation ResearchFundamental and Molecular Mechanisms of Mutagenesis, vol. 480-481, pp. 55-69, 2001.

[74] W. S. Koh, S. Y. Yoon, B. M. Kwon, T. C. Jeong, K. S. Nam, and M. Y. Han, "Cinnamaldehyde inhibits lymphocyte proliferation and modulates T-cell differentiation," International Journal of Immunopharmacology, vol. 20, no. 11, pp. 643-660, 1998.

[75] L. M. Perry, Medicinal Plants of East and Southeast Asia: Attributed Properties and Uses, The MIT Press, Cambridge, Mass, USA, 1980.

[76] H.-S. Lee, S.-Y. Kim, C.-H. Lee, and Y.-J. Ahn, "Cytotoxic and mutagenic effects of Cinnamomum cassia bark-derived materials," Journal of Microbiology and Biotechnology, vol. 14, no. 6, pp. 1176-1181, 2004.

[77] B. Oehler, A. Scholze, M. Schaefer, and K. Hill, "TRPA1 is functionally expressed in melanoma cells but is not critical for impaired proliferation caused by allyl isothiocyanate or cinnamaldehyde," Naunyn-Schmiedeberg's Archives of Pharmacology, vol. 385, no. 6, pp. 555-563, 2012.

[78] E.-H. Chew, A. A. Nagle, Y. Zhang et al., "Cinnamaldehydes inhibit thioredoxin reductase and induce Nrf2: potential candidates for cancer therapy and chemoprevention," Free Radical Biology and Medicine, vol. 48, no. 1, pp. 98-111, 2010.

[79] C. Ekmekcioglu, J. Feyertag, and W. Marktl, "Cinnamic acid inhibits proliferation and modulates brush border membrane enzyme activities in Caco-2 cells," Cancer Letters, vol. 128, no. 2, pp. 137-144, 1998.

[80] L.-T. Ng and S.-J. Wu, "Antiproliferative activity of Cinnamomum cassia constituents and effects of pifithrin-alpha on their apoptotic signaling pathways in Hep G2 cells," Evidence-Based Complementary and Alternative Medicine, vol. 2011, Article ID 492148, 6 pages, 2011.

[81] S.-J. Wu, L.-T. Ng, and C.-C. Lin, "Cinnamaldehyde-induced apoptosis in human PLC/PRF/5 cells through activation of the proapoptotic Bcl-2 family proteins and MAPK pathway," Life Sciences, vol. 77, no. 8, pp. 938-951, 2005.

[82] J. M. Dornish, E. O. Pettersen, and R. Oftebro, "Synergistic cell inactivation of human NHIK 3025 cells by cinnamaldehyde in combination with cis-diamminedichloroplatinum(II)," Cancer Research, vol. 48, no. 4, pp. 938-942, 1988.

[83] J.-H. Zhang, L.-Q. Liu, Y.-L. He, W.-J. Kong, and S.-A. Huang, "Cytotoxic effect of trans-cinnamaldehyde on human leukemia K562 cells," Acta Pharmacologica Sinica, vol. 31, no. 7, pp. 861866, 2010.
[84] K. H. Moon and M. Y. Pack, "Cytotoxicity of cinnamic aldehyde on leukemia L1210 cells," Drug and Chemical Toxicology, vol. 6, no. 6, pp. 521-535, 1983.

[85] H. Niknahad, A. Shuhendler, G. Galati et al., "Modulating carbonyl cytotoxicity in intact rat hepatocytes by inhibiting carbonyl metabolizing enzymes. II. Aromatic aldehydes," ChemicoBiological Interactions, vol. 143-144, pp. 119-128, 2003.

[86] G. G. Hatch, T. M. Anderson, R. A. Lubet et al., "Chemical enhancement of SA7 virus transformation of hamster embryo cells: evaluation by interlaboratory testing of diverse chemicals," Environmental Mutagenesis, vol. 8, no. 4, pp. 515-531, 1986.

[87] A. Stammati, P. Bonsi, F. Zucco, R. Moezelaar, H.-L. Alakomi, and A. Von Wright, "Toxicity of selected plant volatiles in microbial and mammalian short-term assays," Food and Chemical Toxicology, vol. 37, no. 8, pp. 813-823, 1999.

[88] L.-Y. Chuang, J.-Y. Guh, L. K. Chao et al., "Anti-proliferative effects of cinnamaldehyde on human hepatoma cell lines," Food Chemistry, vol. 133, no. 4, pp. 1603-1610, 2012.

[89] J.-Q. Huang, X.-X. Luo, S.-W. Wang, and Y.-H. Xie, "Effect of cinnamaldehyde on activity of tumor and immunological function of S180 sarcoma in mice," Chinese Journal of Clinical Rehabilitation, vol. 10, no. 11, pp. 107-110, 2006.

[90] E.-Y. Moon, M.-R. Lee, A.-G. Wang et al., "Delayed occurrence of $\mathrm{H}$-ras12V-induced hepatocellular carcinoma with long-term treatment with cinnamaldehydes," European Journal of Pharmacology, vol. 530, no. 3, pp. 270-275, 2006.

[91] J. A. Hoskins, "The occurrence, metabolism and toxicity of cinnamic acid and related compounds," Journal of Applied Toxicology, vol. 4, no. 6, pp. 283-292, 1984.

[92] Y. Zhang, X. Y. Yang, Z. S. Kunag, and C. Xiao, "Inhibitory effect of cinnamic acid germanium on growth of uterocervical carcinoma (U14) cells in mice," Linchuang Yu Shiyan Binglixue Zazhi, vol. 26, pp. 467-470, 2010.

[93] L. P. Zhang and Z. Z. Ji, "Synthesis, antiinflammatory and anticancer activity of cinnamic acids, their derivatives and analogues," Acta Pharmaceutica Sinica, vol. 27, no. 11, pp. 817823, 1992.

[94] L. Liu, W. R. Hudgins, S. Shack, M. Q. Yin, and D. Samid, "Cinnamic acid: a natural product with potential use in cancer intervention," International Journal of Cancer, vol. 62, no. 3, pp. 345-350, 1995.

[95] Q. Zhang, Y. Wang, W. Chai et al., "Induced-differentiation effects of cinnamic acid on human osteogenic sarcoma cells cultured primarily in vitro," Zhonghua Zhongliu Fangzhi Zazhi, vol. 16, no. 9, pp. 668-672, 2009.

[96] V. C. G. Soares, C. Bonacorsi, A. L. B. Andrela et al., "Cytotoxicity of active ingredients extracted from plants of the Brazilian 'Cerrado"' Natural Product Communications, vol. 6, no. 7, pp. 983-984, 2011.

[97] E. Bemani, F. Ghanati, L. Y. Boroujeni, and F. Khatami, "Antioxidant activity, total phenolics and taxol contents response of hazel (Corylus avellana L.) cells to benzoic acid and cinnamic acid," Notulae Botanicae Horti Agrobotanici Cluj-Napoca, vol. 40, no. 1, pp. 69-73, 2012.

[98] H. D. Gravina, N. F. Tafuri, A. Silva Júnior et al., "In vitro assessment of the antiviral potential of trans-cinnamic acid, quercetin and morin against equid herpesvirus 1," Research in Veterinary Science, vol. 91, no. 3, pp. e158-e162, 2011. 
[99] K. Ito, T. Nakazato, M. J. Xian et al., "1'-acetoxychavicol acetate is a novel nuclear factor $\kappa \mathrm{B}$ inhibitor with significant activity against multiple myeloma in vitro and in vivo," Cancer Research, vol. 65, no. 10, pp. 4417-4424, 2005.

[100] A. Kondo, H. Ohigashi, A. Murakami, J. Suratwadee, and K. Koshimizu, "1'-Acetoxychavicol acetate as a potent inhibitor of tumor promoter-induced Epstein-Barr virus activation from Languas galanga, a traditional Thai condiment," Bioscience, Biotechnology, and Biochemistry, vol. 57, no. 8, pp. 1344-1345, 1993. 

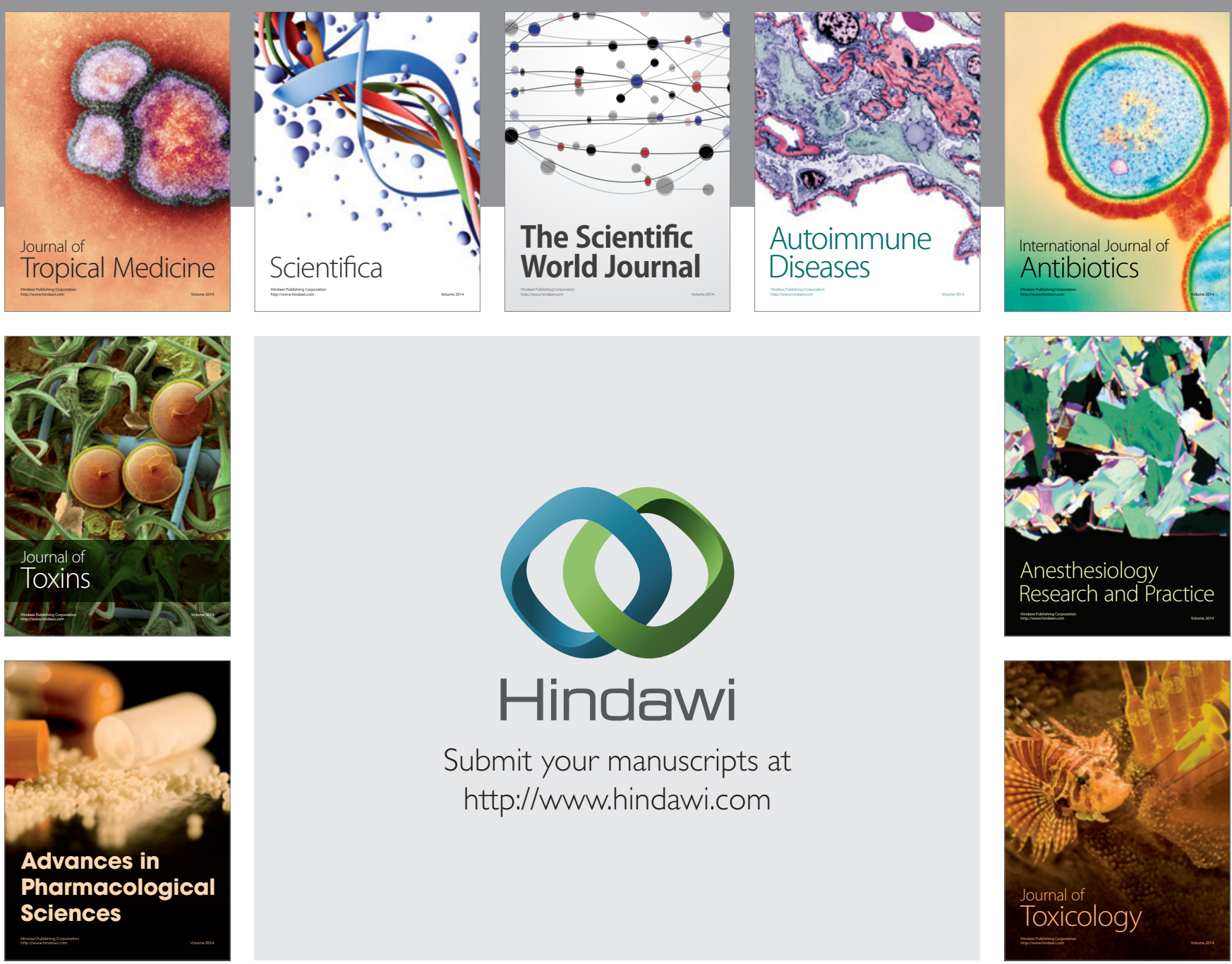

\section{Hindawi}

Submit your manuscripts at

http://www.hindawi.com
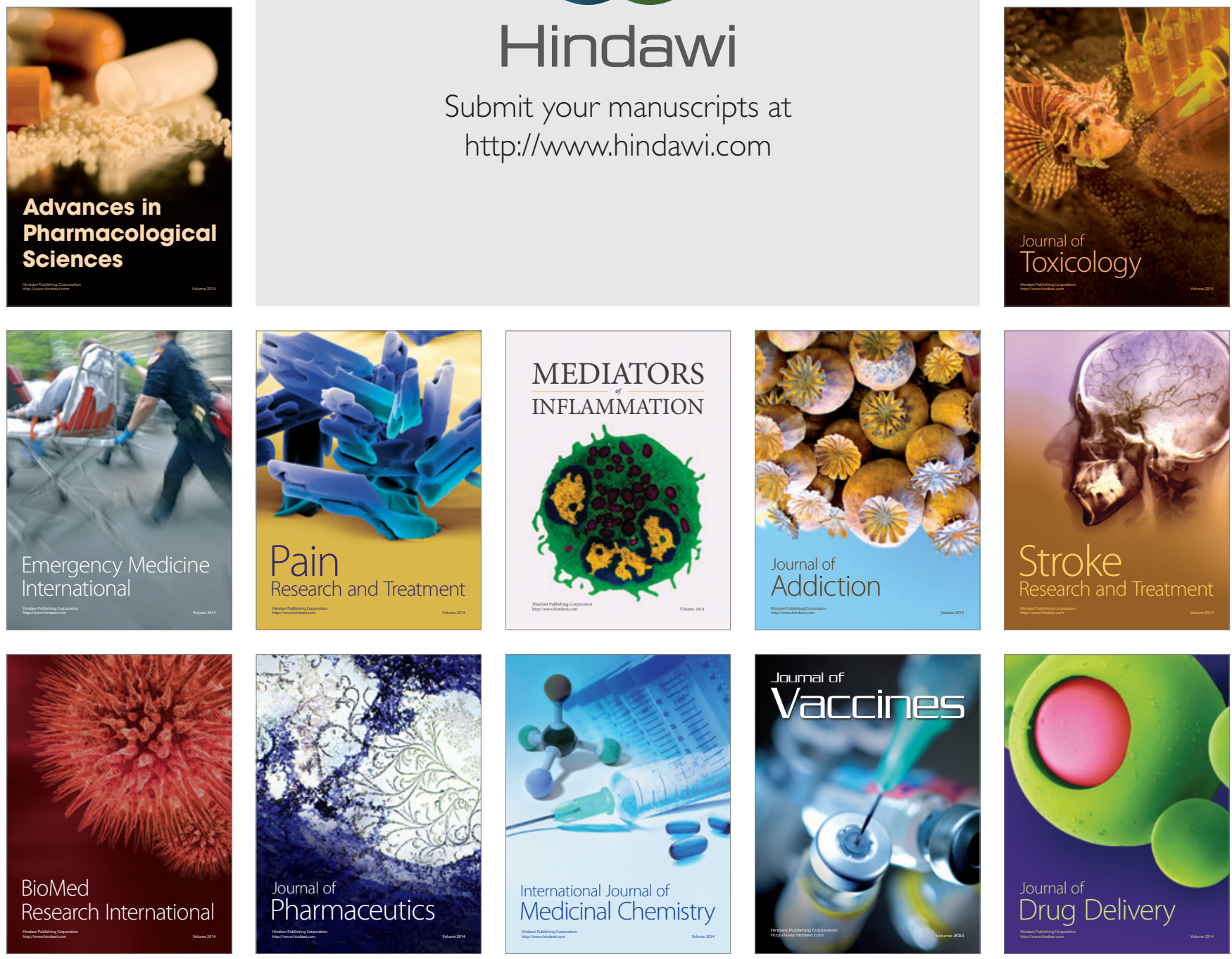